\title{
Effects of Different Glucose-Lowering Measures on Maternal and Infant Outcomes in Pregnant Women with Gestational Diabetes: A Network Meta- analysis
}

Hong Ouyang $\cdot \mathrm{Na} \mathrm{Wu}$

Received: June 28, 2021 / Accepted: August 9, 2021 / Published online: September 4, 2021

(C) The Author(s) 2021

\begin{abstract}
Introduction: A network meta-analysis was conducted to compare and rank the effects of different glucose-lowering measures on maternal and infant outcomes in pregnant women with gestational diabetes mellitus (GDM).

Methods: We searched the PubMed, CNKI, Embase, Cochrane Library, Wanfang, and Weipu databases for relevant studies published between database establishment and June 2021. Study retrieval involved subject-heading and keyword searches. Randomized controlled trials (RCTs) with different glucose-lowering treatments for GDM patients were included. The Cochrane tool was used to assess bias risk. Pairwise and network meta-analyses were used to compare and rank the effects of different hypoglycemic measures on maternal and infant outcomes in pregnant women with GDM.
\end{abstract}

Supplementary Information The online version contains supplementary material available at https:// doi.org/10.1007/s13300-021-01142-7.

H. Ouyang · N. Wu (ه)

Department of Endocrinology, Shengjing Hospital of China Medical University, Shenyang, China e-mail: 3441535223@qq.com

N. Wu

Clinical Skills Practice Teaching Center, Shengjing Hospital of China Medical University, Shenyang, China
Results: We included 41 RCTs involving 6245 pregnant women with GDM. Patients treated with insulin had a higher incidence of neonatal intensive care unit (NICU) occupancy $(1.3,95 \%$ CI 1.0-1.7) than those treated with metformin. The insulin $(1.5,95 \%$ CI $1.1-2.1$ and $1.8,95 \%$ CI 1.0-3.3) and glyburide (2.0, 95\% CI 1.2-3.2 and $2.5,95 \%$ CI 1.1-8.4) groups exhibited higher incidences of neonatal hypoglycemia and large for gestational age (LGA) newborns than the metformin group. The glyburide group exhibited a lower probability of cesarean section than the metformin $(0.76,95 \%$ CI $0.55-1.0)$ and insulin (0.71, 95\% CI 0.52-0.96) groups. Preeclampsia incidence in the diet and exercise groups was significantly lower than in the metformin $(0.19$, 95\% CI 0.043-0.72) and insulin (0.15, 95\% CI $0.032-0.52)$ groups. No intervention significantly reduced the incidences of macrosomia, preterm birth, gestational hypertension, or respiratory distress syndrome (RDS). The ranking results showed that the metformin group had the lowest rates of neonatal hypoglycemia, macrosomia, LGA, and NICU occupancy. The glyburide group had the lowest NICU occupancy and cesarean section rates and the highest neonatal hypoglycemia, LGA, preeclampsia, and gestational hypertension rates. The diet and exercise group had the lowest preterm delivery and preeclampsia rates and the highest NICU occupancy rate.

Conclusion: Metformin is a potentially superior choice for GDM treatment because it is 
associated with minimal incidences of multiple adverse pregnancy outcome indicators and does not lead to high values of certain adverse outcome indices. Other hypoglycemic agent or diet groups exhibit high incidences of certain adverse outcomes. Therefore, when selecting a GDM treatment strategy, the efficacies and risks of different treatment programs should be evaluated according to the scenario in hand.

Keywords: Metformin; Insulin; Glyburide; Diet and exercise; Gestational diabetes; Maternal and infant outcome; Randomized controlled trials

\section{Key Summary Points}

\section{Why carry out this study?}

In recent years, traditional meta-analyses have been used to compare the efficacies and safety of OADs with those of insulin in the treatment of GDM. However, the results have been inconsistent due to a lack of evidence from head-to-head randomized controlled trials (RCTs).

Network meta-analysis (NMA) uses direct and indirect data to compare

interventions (e.g., in terms of their therapeutic effects) and thus identify the most effective options. Therefore, in order to further evaluate the effects of different treatments, including diet and exercise, OADs, and insulin, on maternal and infant outcomes for pregnant women with GDM, we conducted an NMA of relevant RCTs to elucidate the efficacies and safety of different treatments and thus provide better evidence upon which to base GDM treatment decisions.

\section{What was learned from this study?}

Metformin is a potentially superior choice for GDM treatment because it is associated with minimal incidences of multiple adverse pregnancy outcome indicators and does not lead to high values of certain adverse outcome indices.
Vitamin D is closely linked to GDM. In the future, GDM treatment should not only involve the selection of appropriate hypoglycemic drugs but should also account for the role of vitamin D in GDM.

Assisted reproductive technology (ART) may have an effect on the maternal and infant outcomes of pregnant women with gestational diabetes.

\section{INTRODUCTION}

Gestational diabetes mellitus (GDM) is defined as abnormal hyperglycemia or glucose tolerance-as identified through oral glucose tolerance trials-that first occurs during pregnancy, usually at $24-28$ weeks $[1,2]$. It is one of the most common complications of pregnancy [3]. GDM is a major global public health issue due to its increasing prevalence in recent years as a result of changing lifestyles, the increased average age of pregnant women, and the prevalence of obesity and type 2 diabetes $[4,5]$. In statistics from the International Diabetes Federation (IDF), GDM prevalence is included in the hyperglycemia in pregnancy (HIP) data, which are tallied together with the diabetes in pregnancy (DIP) data. According to the regional distribution of diabetes published by the IDF in 2019, the global prevalence of HIP was $15.8 \%$ while the global prevalence of GDM was $12.8 \%$ [6].

Christoph et al. highlighted the influence of early life events on susceptibility to diseases in later life, referring to insulin resistance as a major cause of anthropometric changes at birth and susceptibility to diseases in later life [7]. In 2019, a study further highlighted the link between insulin resistance and low birth weight, suggesting that insulin resistance increases the incidence of low birth weight, which leads to an increased risk of neonatal and infant death and is associated with higher rates of diabetes, cardiovascular disease, and kidney disease in adults [8]. Pregnant women with 
GDM have higher insulin resistance, which increases the incidences of hypertension, depression, and cesarean section during pregnancy as well as their susceptibility to type 2 diabetes mellitus, cardiovascular disease, dyslipidemia, and metabolic disorders after delivery [9-11]. In addition, children of pregnant women with improperly treated GDM are more at risk of neonatal hypoglycemia, neonatal jaundice, macrosomia, and respiratory distress syndrome (RDS) [12, 13]. Therefore, active blood glucose control is of paramount importance for optimizing maternal and infant prognoses. Blood glucose control during pregnancy mainly relies on health intervention, drugs, and self-monitoring of blood glucose [14]. Currently, the American Diabetes Association (ADA), IDF, National Institutes of Health and Healthcare, and other agencies all recommend prioritizing diet therapy as a means to achieve normal blood glucose levels [15-17]. However, for patients who do not effectively control their blood glucose through their diet, exercise, insulin, or oral antidiabetic drugs (OADs) are needed. Insulin has always been the preferred treatment for GDM women. Also, multiple daily injections, the occurrence of hypoglycemia, increased appetite, and weight gain make it difficult for many pregnant women to choose an intervention [18]. In contrast, OADs are more manageable and less expensive, so they have emerged as an attractive alternative to insulin [19]. They are also used as part of routine GDM treatment according to the latest treatment guidelines released by the International Diabetes Alliance in 2009. At present, OADs commonly used in GDM treatment can be divided into the following three categories: insulin secretion promoters (e.g., glyburide), insulin sensitizers (e.g., metformin), and alphaglucosidase inhibitors (e.g., acarbose) [20].

In recent years, traditional meta-analyses have been used to compare the efficacies and safety of OADs with that of insulin in the treatment of GDM. However, the results have been inconsistent due to a lack of evidence from head-to-head randomized controlled trials (RCTs). In an early study in 2000, Hellmuth et al. compared the efficacies of metformin, sulfonylurea, and insulin in GDM treatment and found that metformin administration during pregnancy potentially increases the prevalence of preeclampsia and that of perinatal mortality. They therefore concluded that treatment of GDM with metformin increases the risk of adverse maternal and infant events [21]. However, the results of a large RCT published in 2008 demonstrated that metformin alone or metformin with insulin are safe and effective treatment options for GDM [22]. Studies have also found glyburide to be as effective as insulin at improving blood glucose levels in GDM, but that glyburide is associated with greater risks of macrosomia, neonatal hypoglycemia, and low birth weight [23]. However, another study found it to be a more effective GDM treatment than metformin, with lower failure rates [24]. Therefore, the most beneficial hypoglycemic drug for patients with GDM remains unclear. Network meta-analysis (NMA) can use direct and indirect data to compare interventions (including their therapeutic effects) and thus identify the most effective options. Therefore, in order to further evaluate the effects of different treatments, including diet and exercise, OADs, and insulin, on maternal and infant outcomes in pregnant women with GDM, we conducted an NMA of relevant RCTs to elucidate the efficacies and safety of different treatment methods and thus provide better evidence upon which to base GDM treatment decisions. This article is based on previously conducted studies and does not contain any new studies with human participants or animals performed by any of the authors and therefore ethical approval was not required.

\section{METHODS}

\section{Search Strategy}

Using a computer, we retrieved studies from the PubMed, Chinese Journal Full Text (CNKI), EMBASE, Cochrane Library, Wan Fan, and Wei $\mathrm{Pu}$ databases for relevant studies published between the inception of the database and June 2021. Study retrieval involved a combination of subject-heading and keyword searches. Search terms included "gestational diabetes," "oral 
hypoglycemic drugs," "oral antidiabetic drugs", "metformin," "insulin," "glyburide," "acarbose," "diet and exercise," and "maternal and infant outcomes." The publication type of retrieved studies was limited to RCTs (with no language or site restrictions) (Supplementary Table 1).

\section{Inclusion and Exclusion Criteria}

Studies included in the NMA met the following criteria: (1) the subjects were pregnant women with gestational diabetes diagnosed by various diagnostic criteria; (2) the study was an RCT; (3) at least one valid indicator of maternal and infant outcomes was included (neonatal indicators: neonatal hypoglycemia, macrosomia, RDS, NICU, LGA, and preterm delivery; maternal indicators: cesarean section, preeclampsia, gestational hypertension); (4) the efficacies and safety of different OADs were compared with the efficacy and safety of insulin or diet and exercise in pregnant women with GDM.

Exclusion criteria: (1) the design of the study did not qualify it as a randomized controlled study (thus excluding reviews, reviews, letters, and others); (2) the study did not meet the diagnostic criteria for GDM; (3) patients had comorbidities such as congenital adrenal hyperplasia, Cushing's syndrome, androgen-secretory tumors, hyperprolactinemia, severe kidney disease, or liver disease; (4) patients had a previous history of diabetes.

\section{Data Extraction and Quality Evaluation}

Two assessors independently searched the databases to identify the literature according to the inclusion and exclusion criteria, and, for each study retrieved, recorded the first author's name, the publication year, the country in which the study was performed, the diagnostic criteria used for GDM, the interventions applied, the drug doses used, the demographics of the study subjects (sample size, average body mass index, age), and the results (both maternal and neonatal). The methodological quality of the study was evaluated in accordance with the Offset Risk Assessment Tool of the Cochrane System Evaluator Manual, version 5.1.0. Evaluated aspects included the following: random sequence generation, hidden distribution concealment, the blinding of subjects and intervention providers, the blinding of result evaluation, the integrity of the outcome data, selective result reporting, and other sources of bias. When there was inconsistency, judgment was reached through public discussion. In accordance with the Cochrane Collaboration Group criteria, we divided the studies into three categories: (1) low bias risk (low bias risk in all key areas), (2) unclear bias risk (unclear bias risk in one or more key areas), and (3) high bias risk (high bias risk in one or more key areas).

\section{Statistical Analysis}

\section{Direct Meta-analysis (DMA)}

For DMA, we used the RevMan5.3 software provided by Cochrane for statistical analysis, with the relative hazard (RR) and 95\% confidence interval (CI) used as the evaluation indices for the results (represented by the mean difference and 95\% CI). First, heterogeneity was assessed using the $X^{2}$ test $(a=0.05)$, and a quantitative analysis of $I^{2}$ for heterogeneity $\left(I^{2} \geq 50 \%\right)$ was conducted. The meta-analysis was conducted when there was no heterogeneity between the research results. When there was statistical heterogeneity between the research results, the source of heterogeneity was analyzed further and the random heterogeneity model was used after excluding the influence of obvious clinical heterogeneity. Funnel maps created using the Stata software were employed to detect publication bias.

\section{Network Meta-analysis}

We performed a Bayesian NMA using R (version 3.3.2) and the STATA 12.0 software. NMA can combine direct and indirect comparisons to further analyze the effects of different treatment options on maternal and infant outcomes for pregnant women with GDM. The results of the comparisons were expressed as the RR and its 95\% CI. Moreover, we built a network diagram using the mtc.network "command of the gemtc" package in the R software. Furthermore, we calculated the percentage area under the cumulative ranking (SUCRA) curve to rank the 
different interventions. One intervention had a higher SUCRA value than the others, indicating the greater the treatment effect, the lower the incidence of adverse reactions. A node-splitting method was used to evaluate the hypothesis of consistency between direct and circumstantial evidence. When direct evidence of the results was consistent with circumstantial evidence $(P>0.05)$, the consistency model was adopted.

\section{RESULTS}

\section{Retrieved Results}

Following a predesigned literature retrieval strategy, 683 articles were retrieved, but this included 243 duplicate articles. After reviewing the titles and abstracts, another 375 were excluded, thus leaving 65 articles in detail. After further review, some of these articles were excluded for the following reasons: the studies in 8 articles did not include clear outcome indicators, the studies in another 8 articles did not conform to the RCT study design, the studies in 4 articles included subjects who did not meet the GDM diagnostic criteria, and the studies in 5 articles included subjects with comorbidities. Finally, we included 41 RCTs involving a total of 6245 pregnant women with GDM. The literature screening process and the results are shown in Fig. 1.

\section{Features Incorporated into the Study}

The basic features of the included studies are shown in Table 1 . The included studies were published between 2000 and 2021, with 15 studies [25-30, 46-53, 63] originating from Asia, 7 from North America [31-35, 57, 58], 7 from Europe $[36-40,61,62], 5$ from South America [41-45], 3 from Africa [54-56], and 2 from New Zealand $[59,60]$.

For GDM diagnosis, 13 studies adopted the International Diabetes and Pregnancy Research Group standards, 7 adopted the World Health

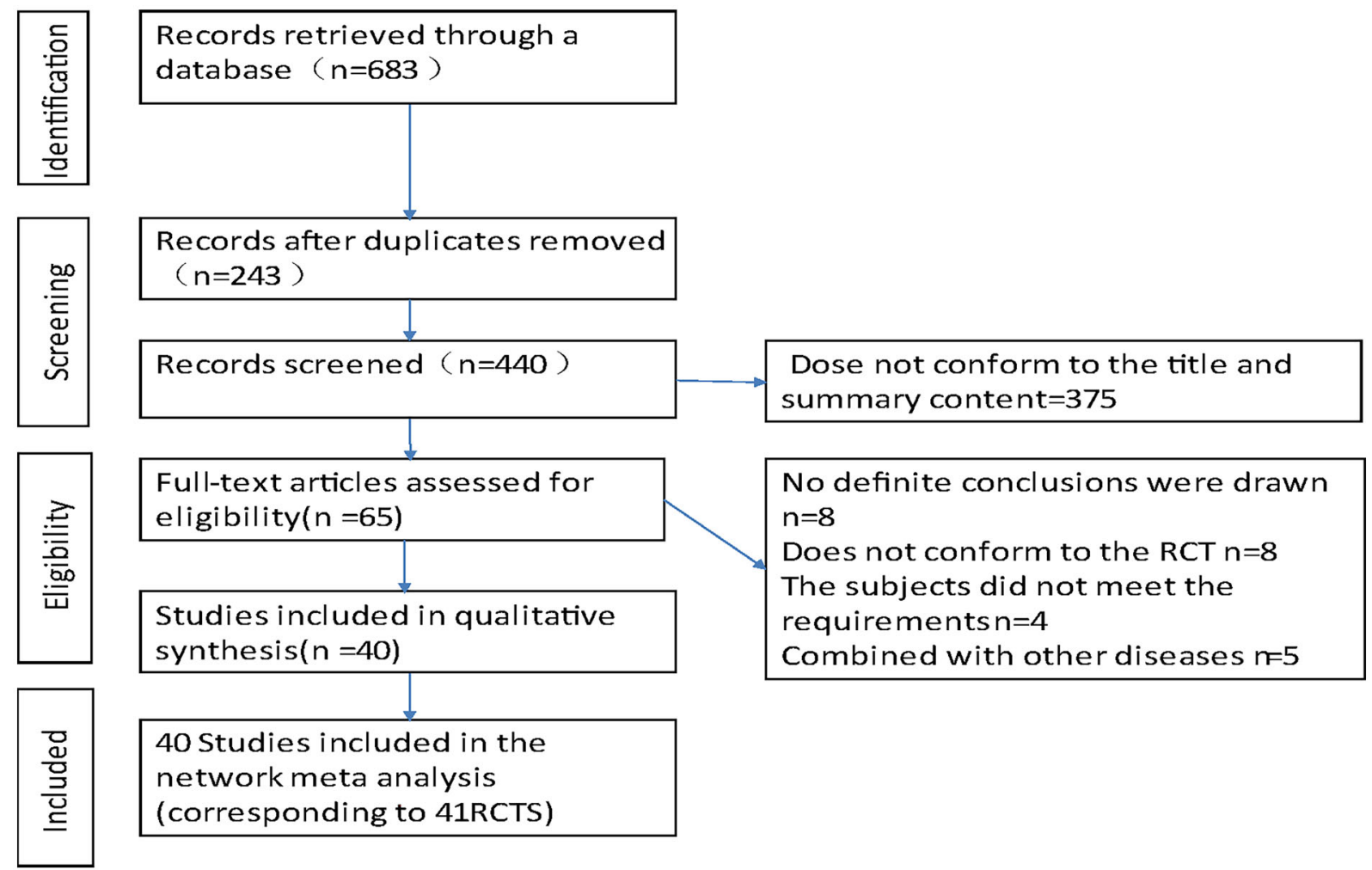

Fig. 1 Flow diagram of the study selection process 


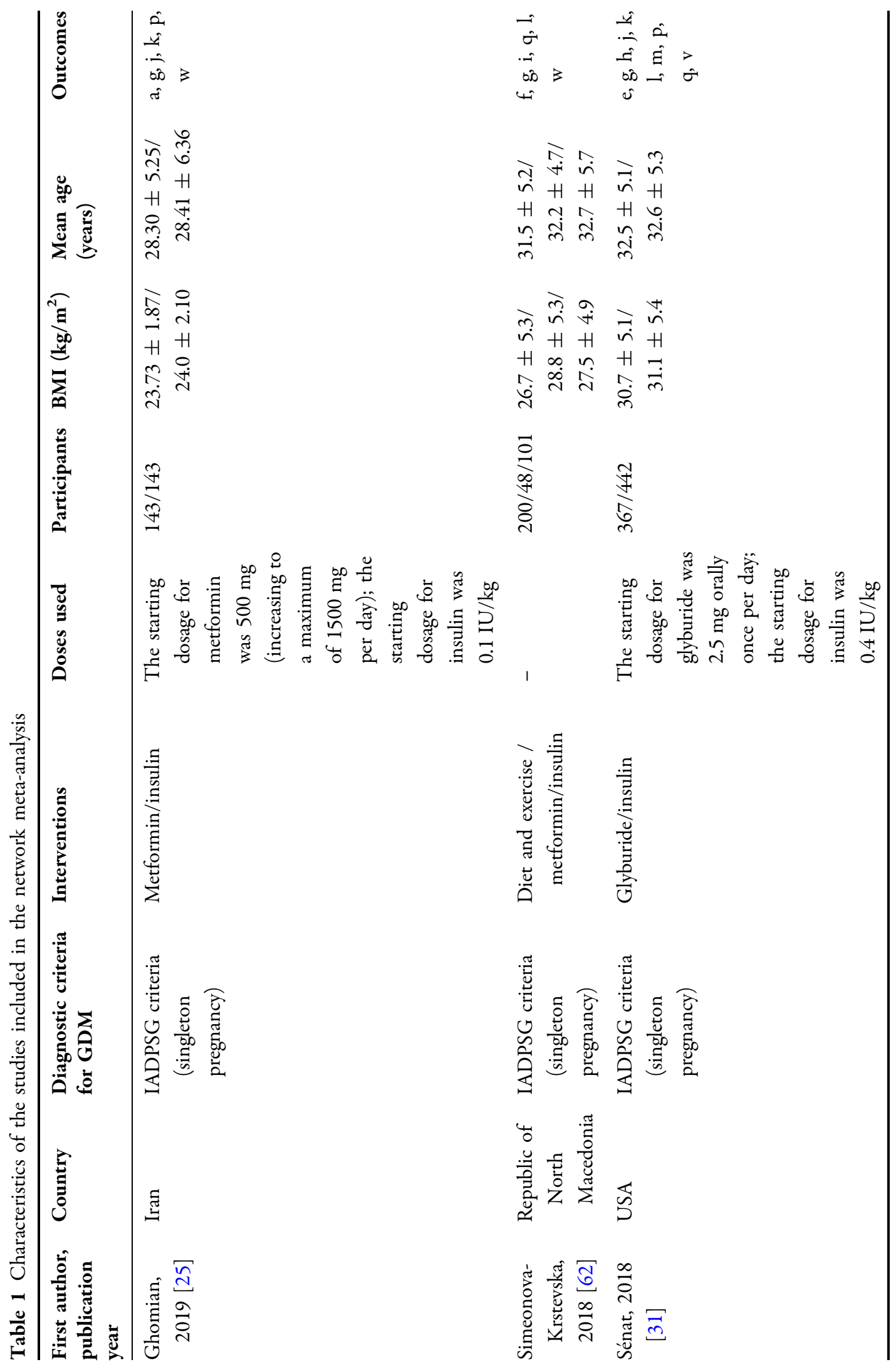




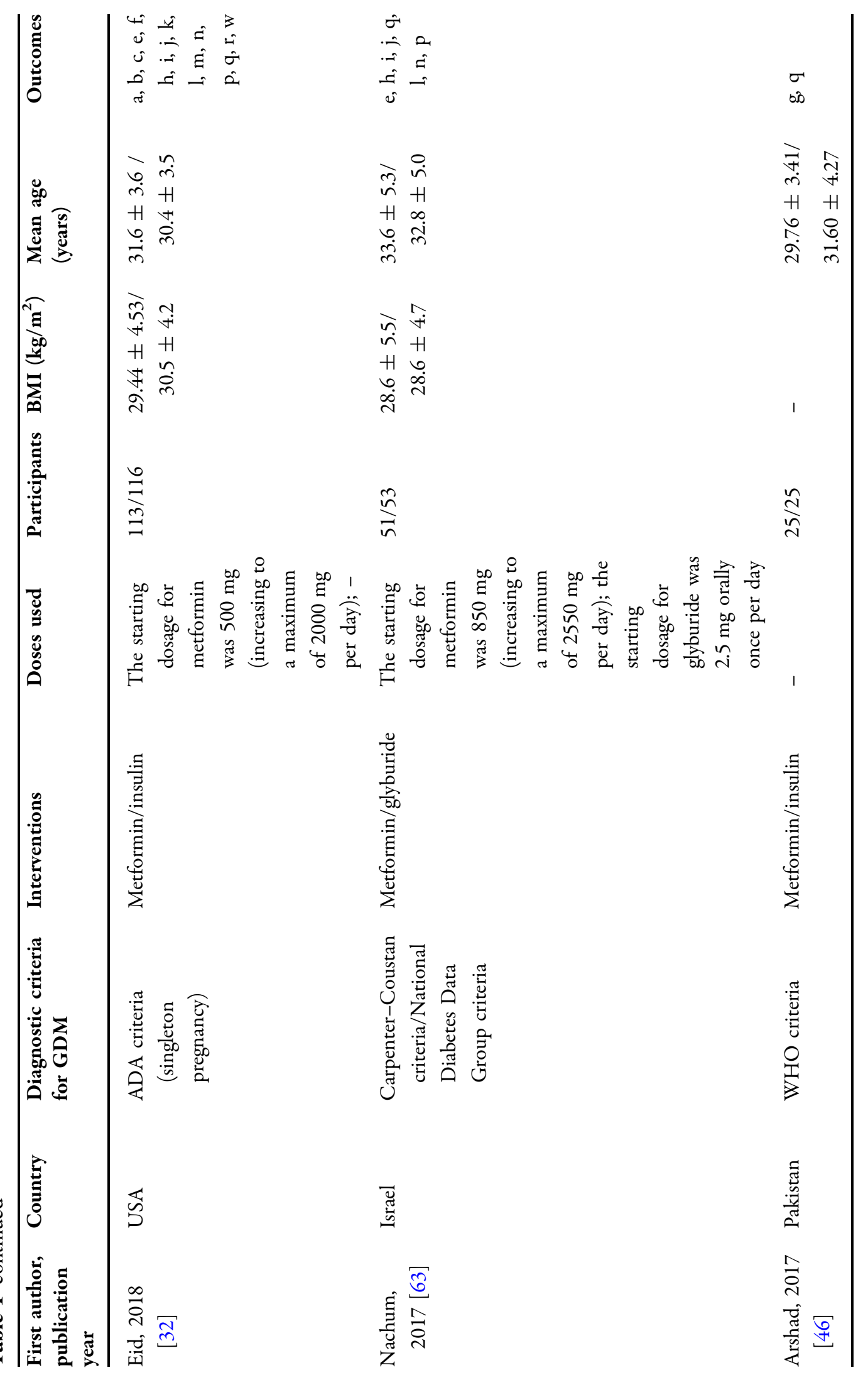




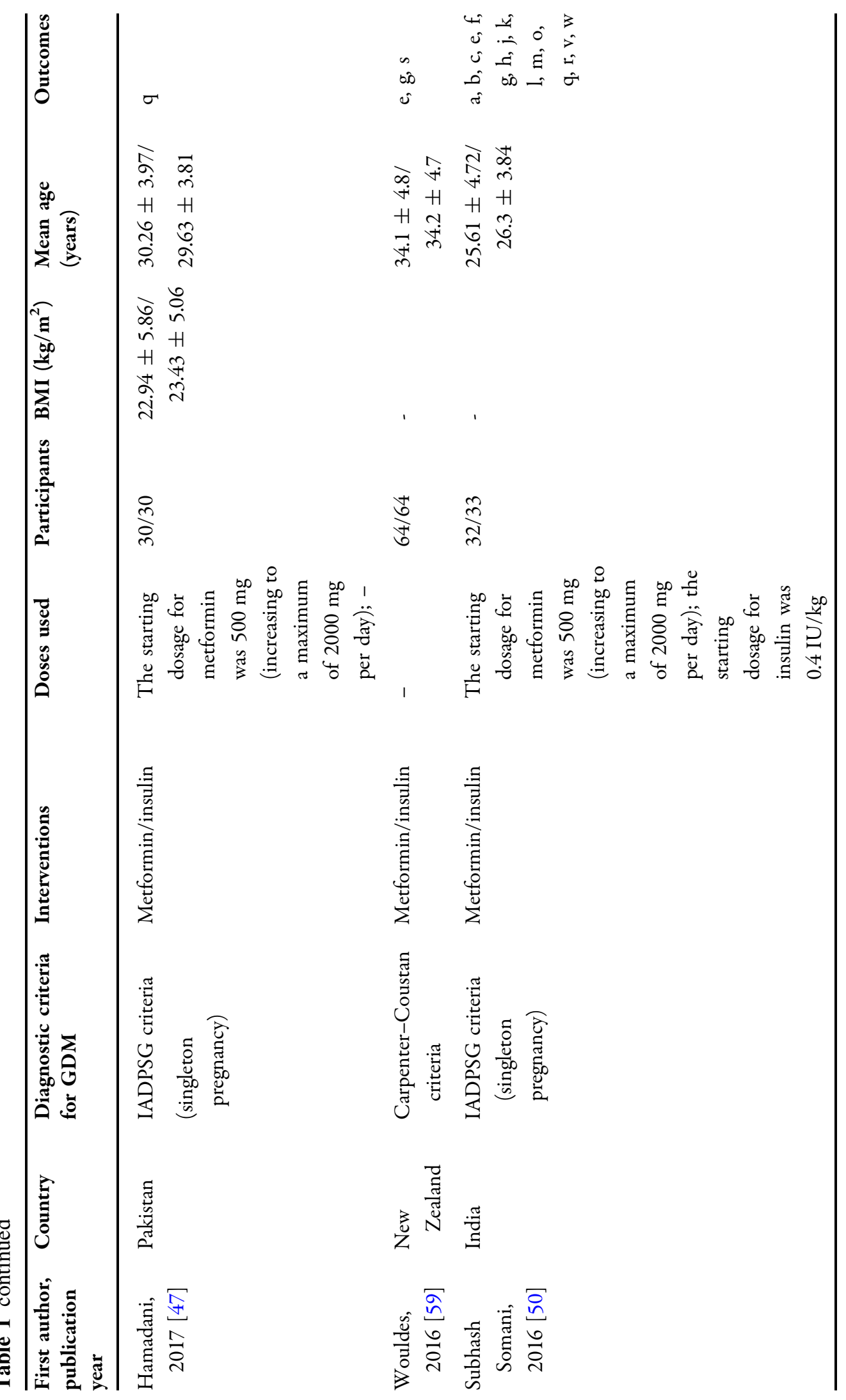




\begin{tabular}{|c|c|c|}
\hline $\begin{array}{l}\mathscr{ٌ} \\
\ddot{\Xi} \\
\ddot{\Xi} \\
0\end{array}$ & 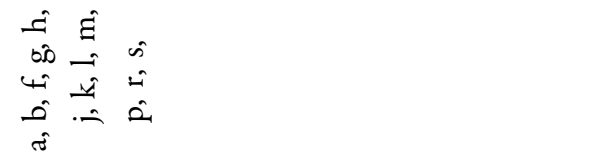 & 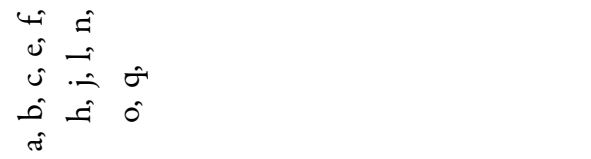 \\
\hline 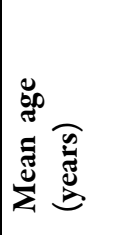 & 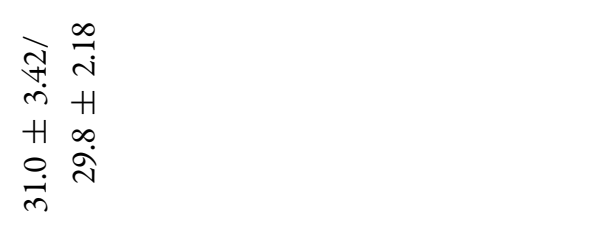 & 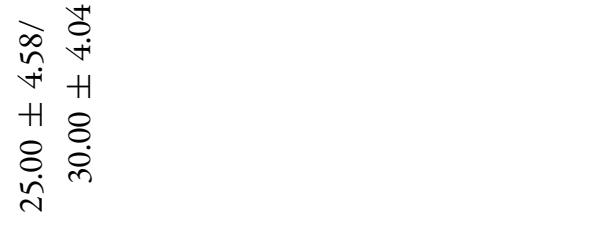 \\
\hline 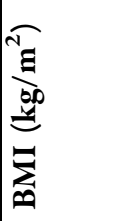 & 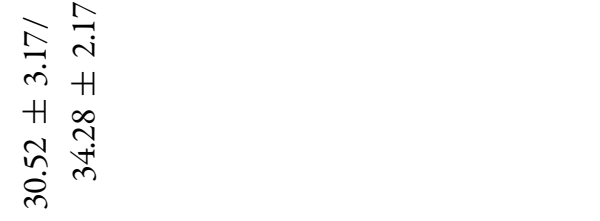 & 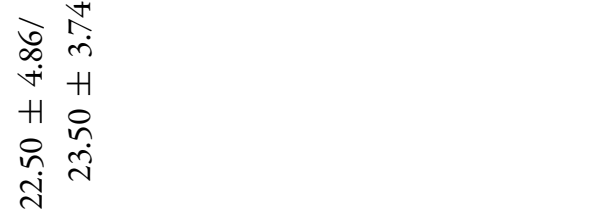 \\
\hline D. & $\stackrel{尺}{\circledR}$ & $\stackrel{\substack{n \\
i}}{n}$ \\
\hline 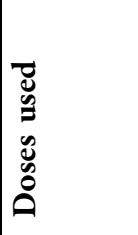 & 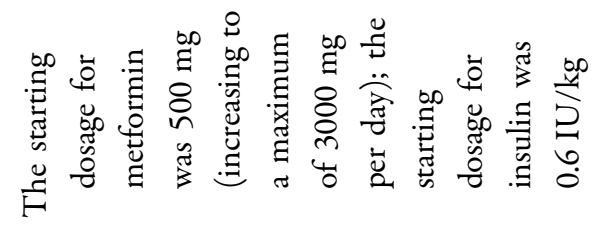 & 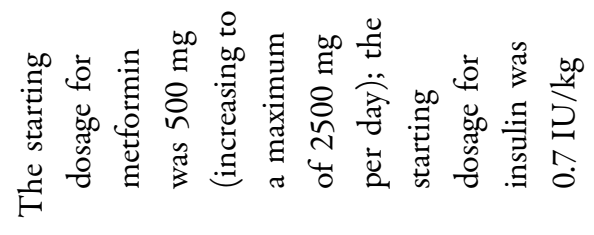 \\
\hline 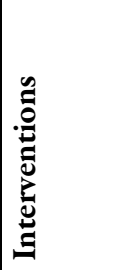 & 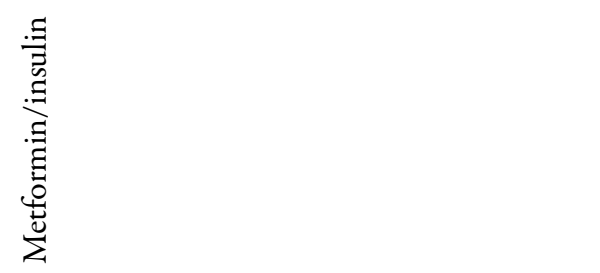 & 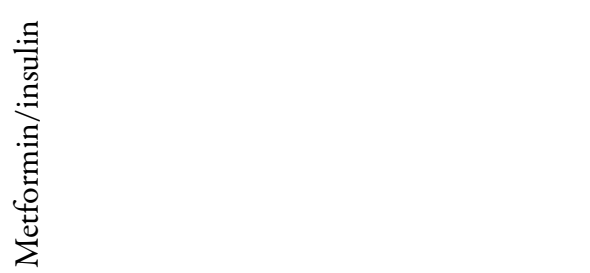 \\
\hline 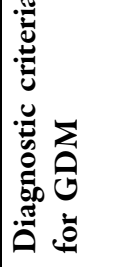 & 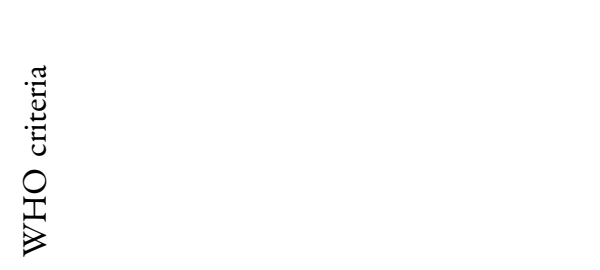 & 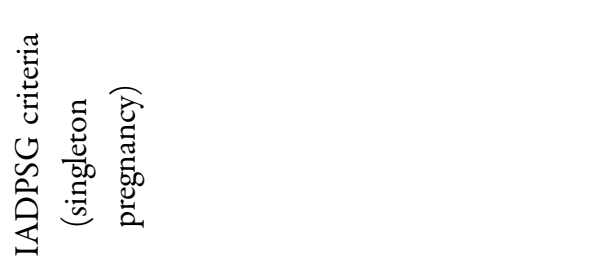 \\
\hline ن & 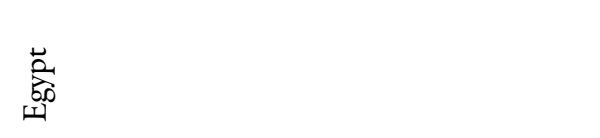 & 蒿 \\
\hline 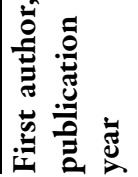 & 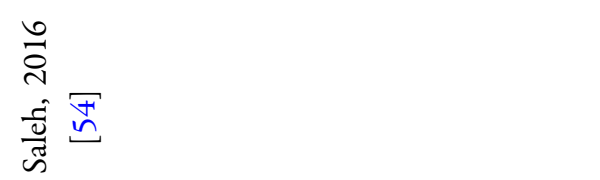 & 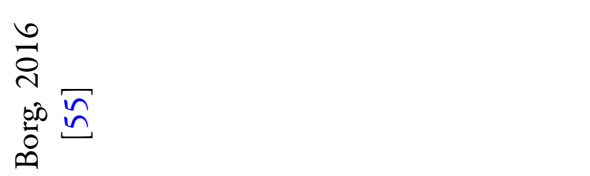 \\
\hline
\end{tabular}




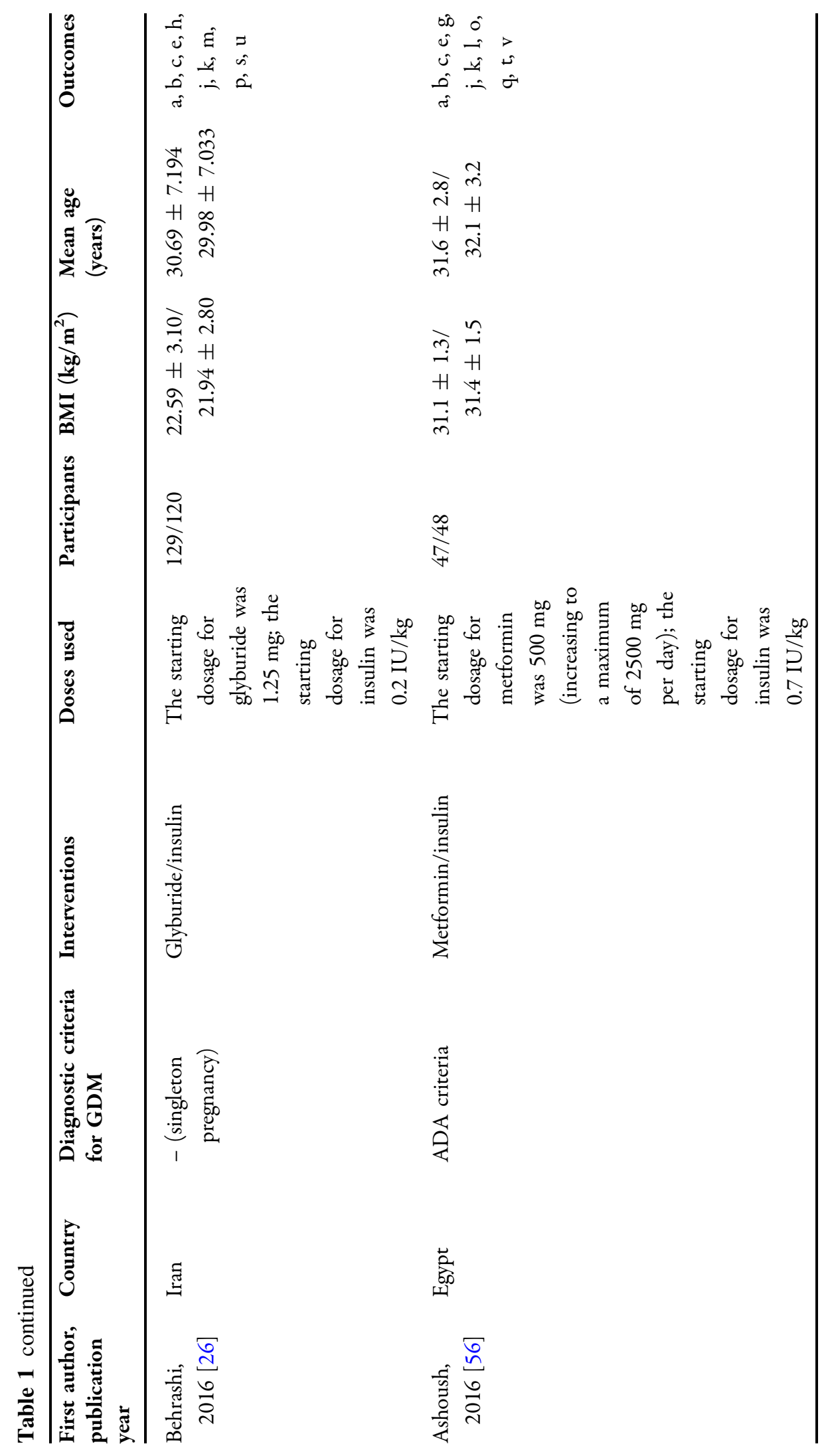




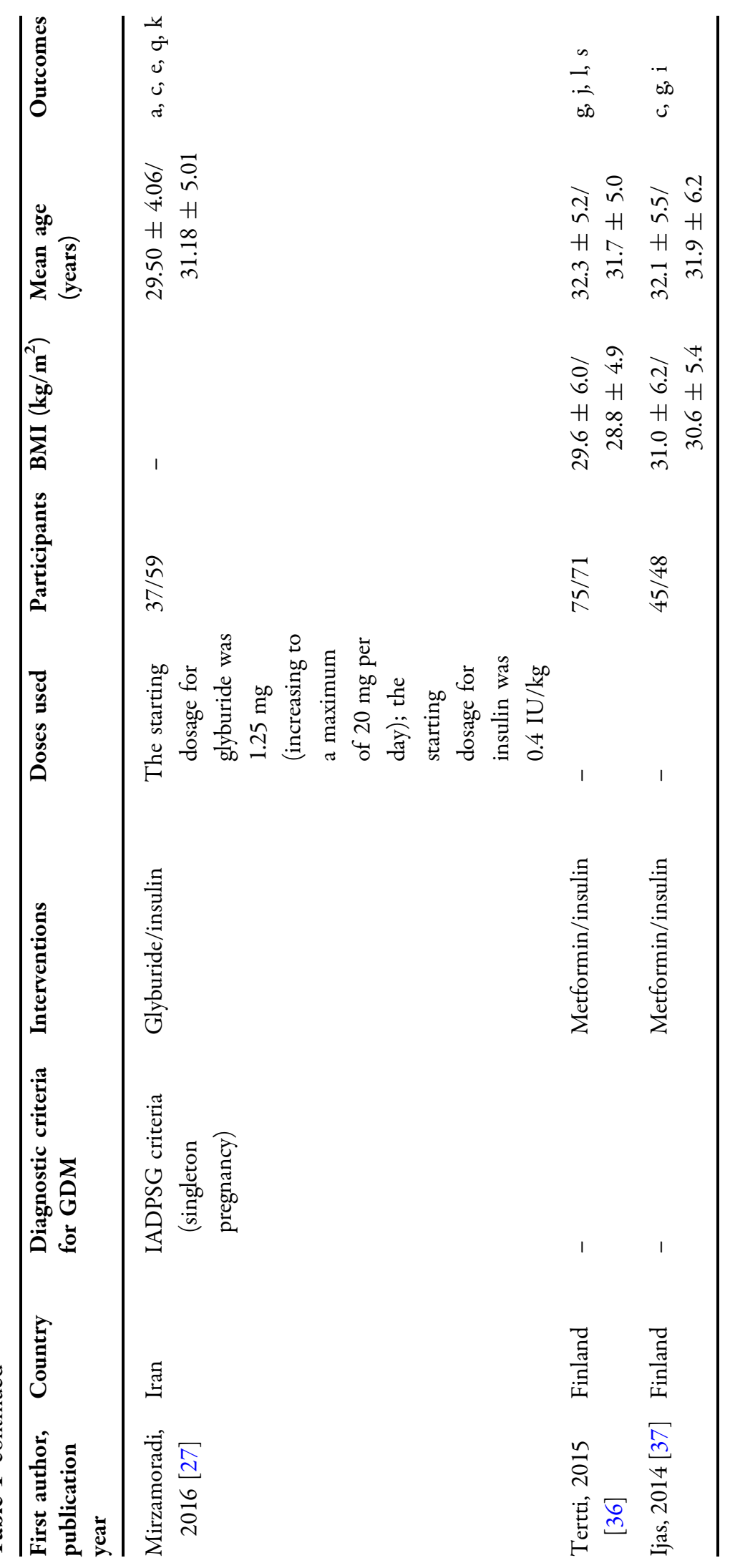




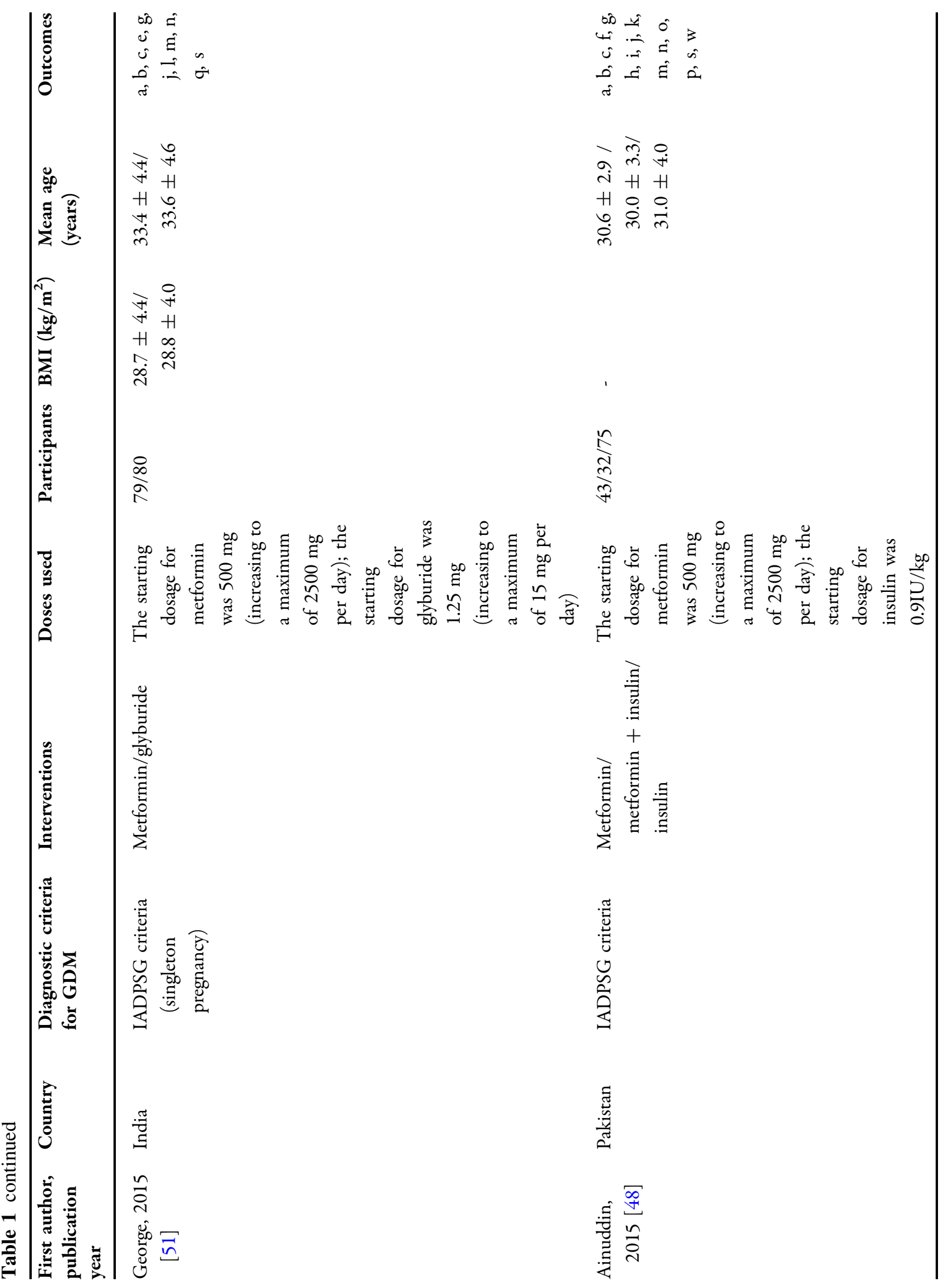




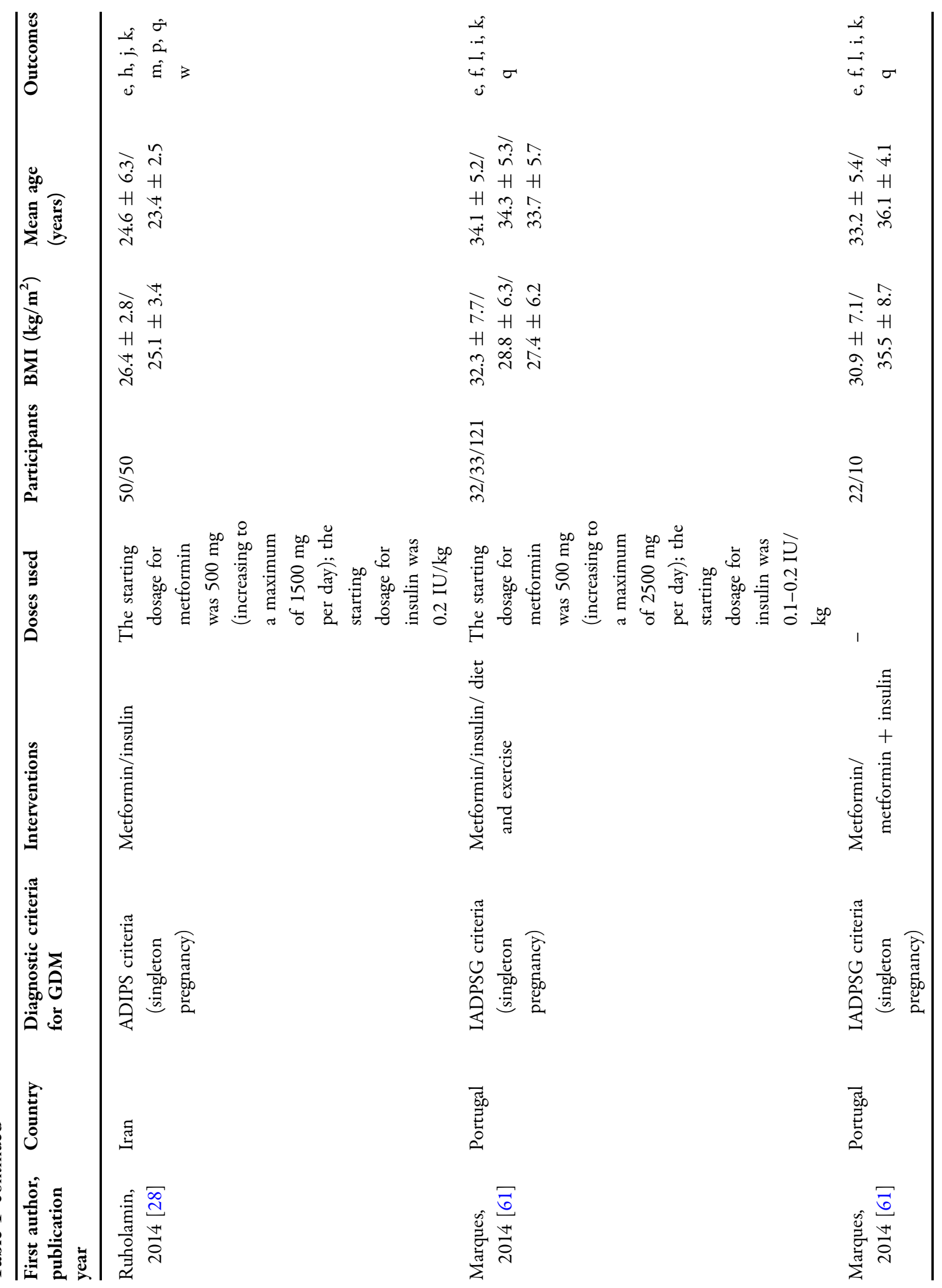




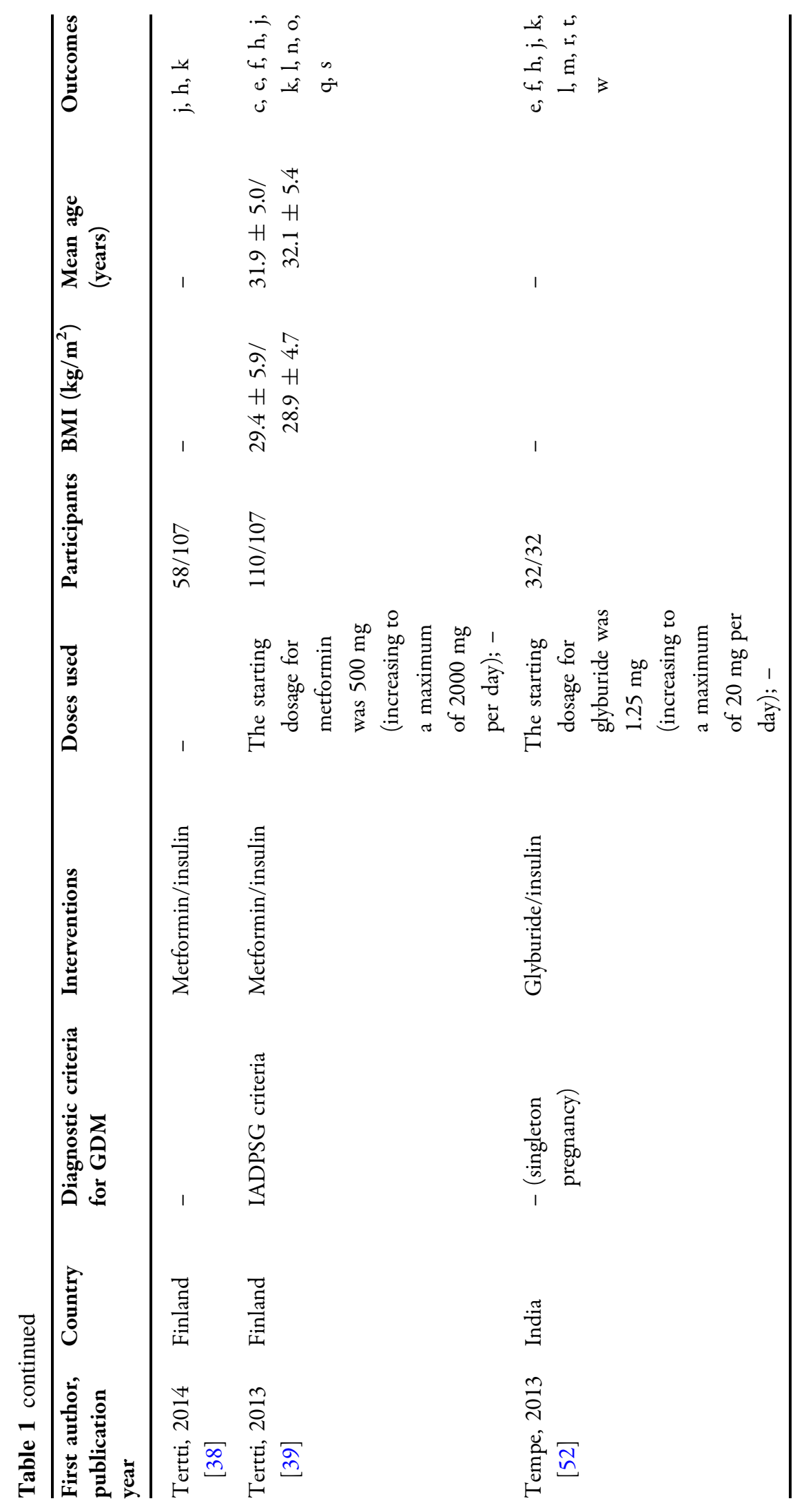




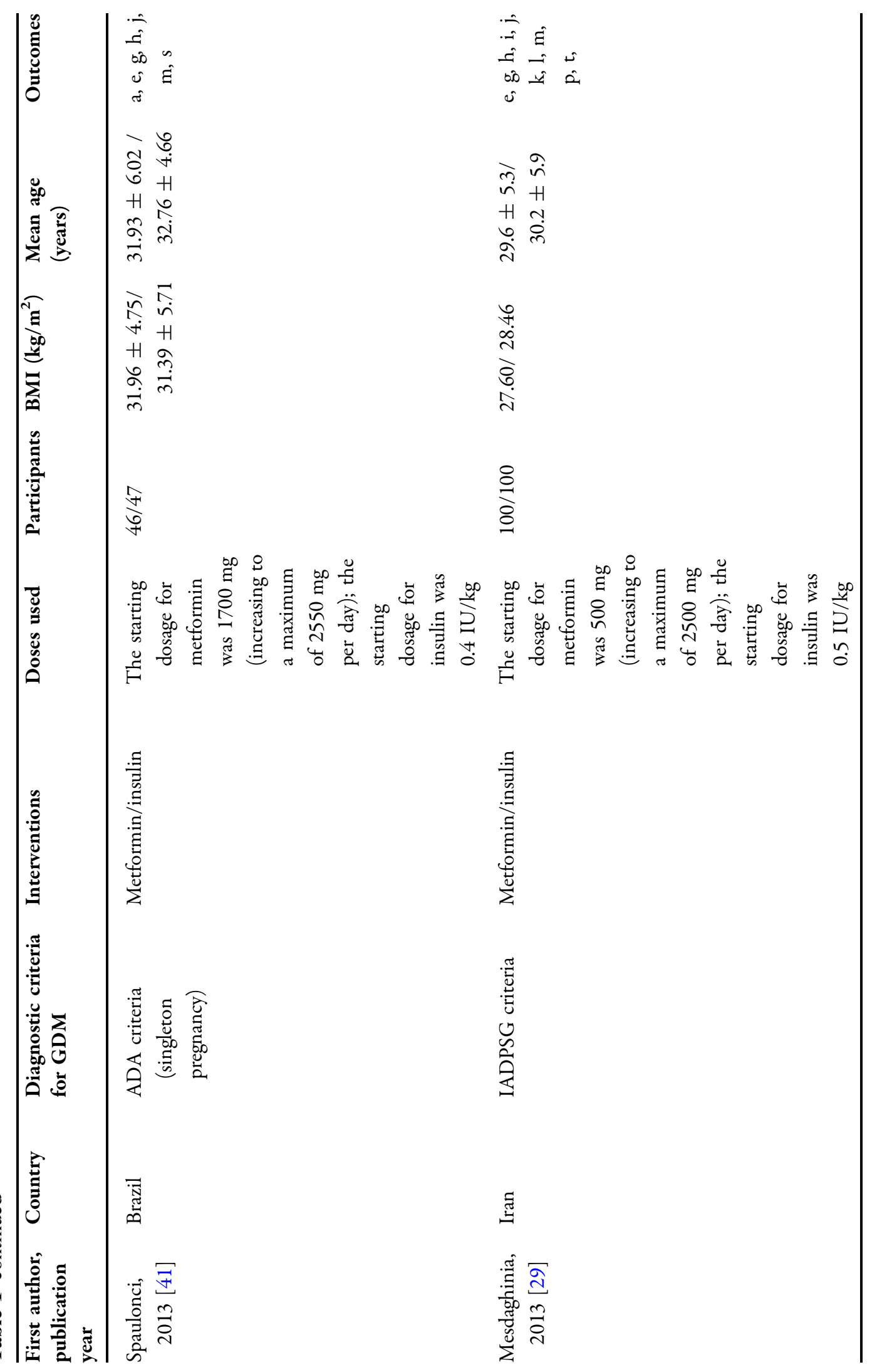




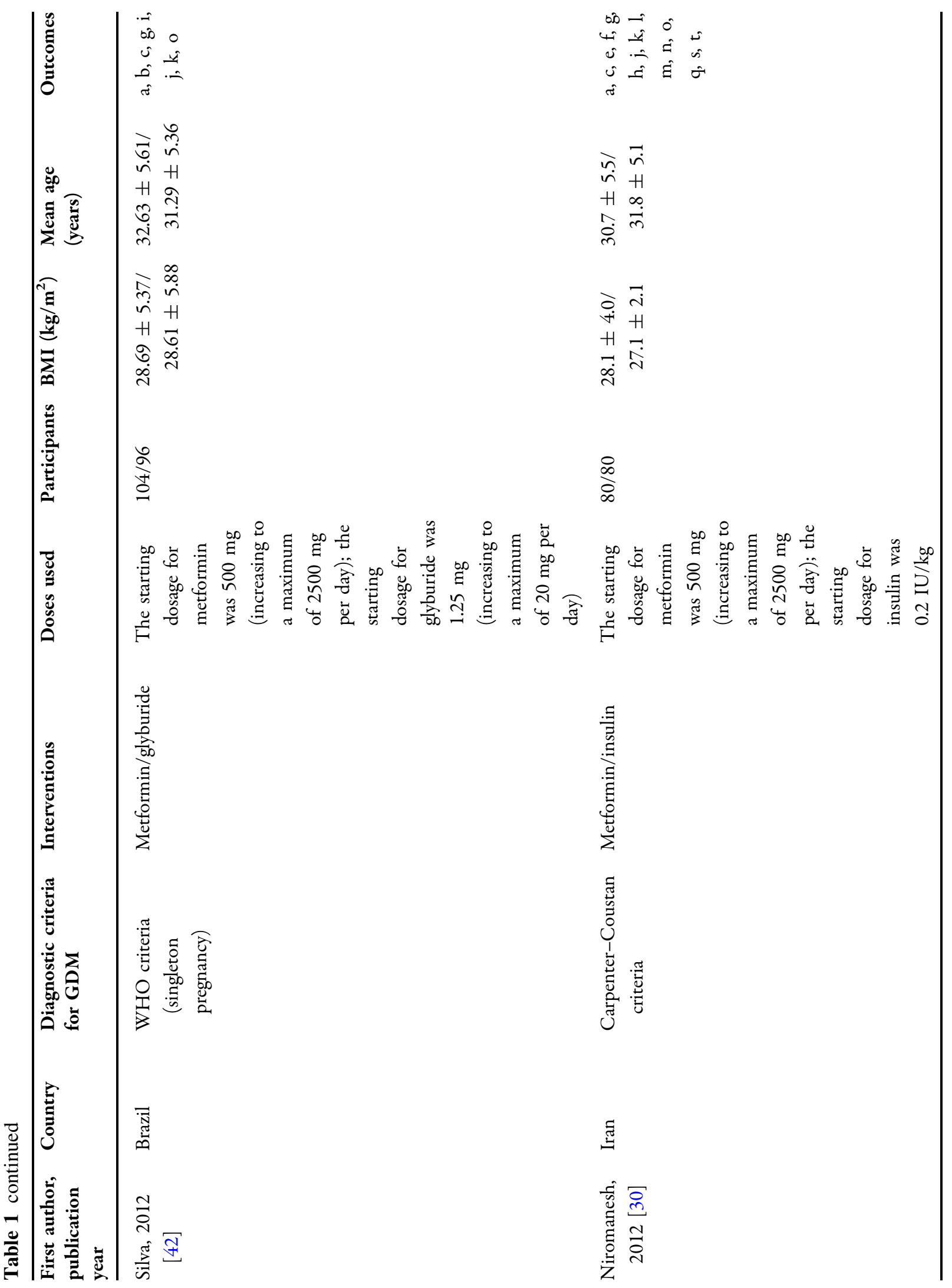




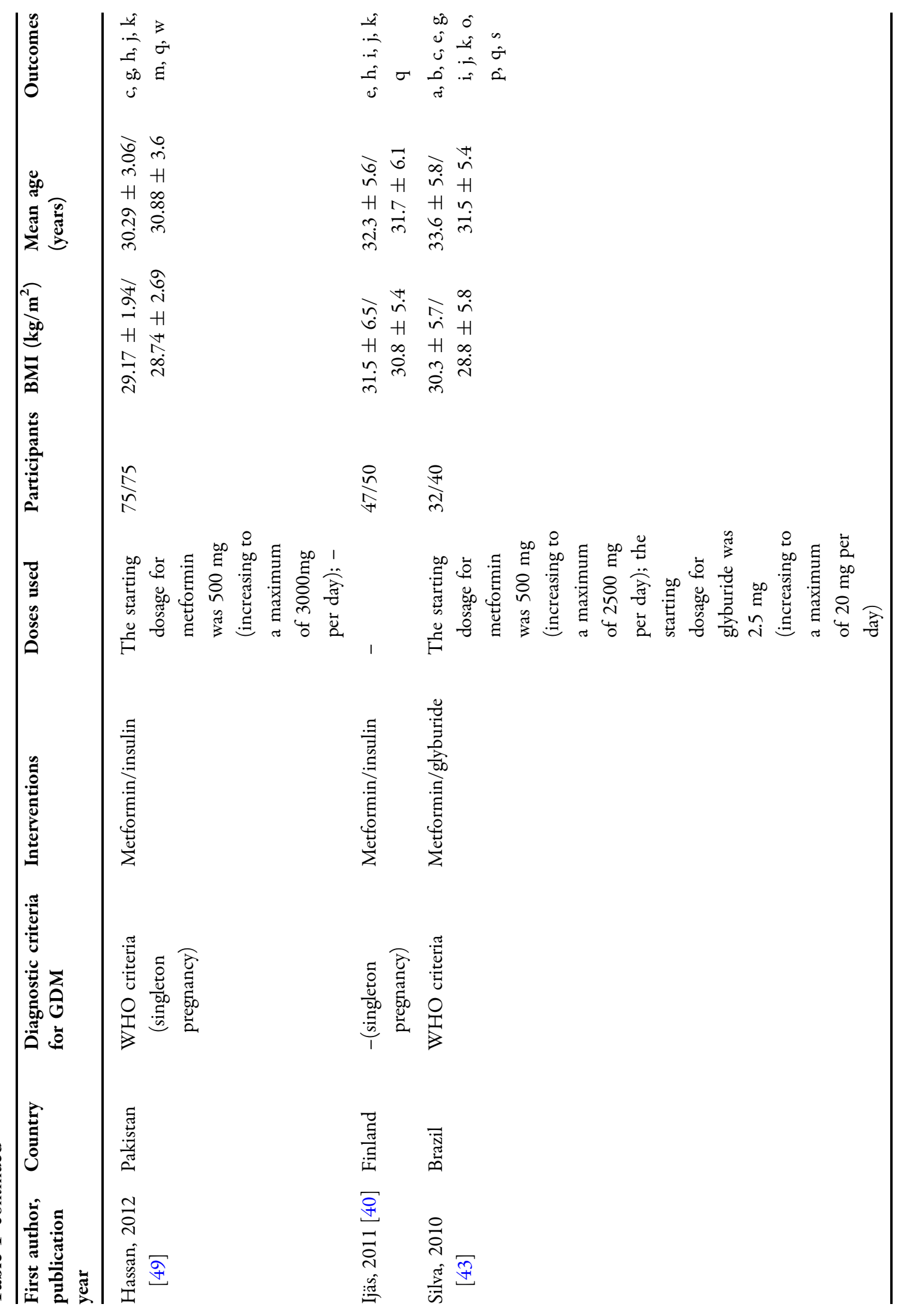




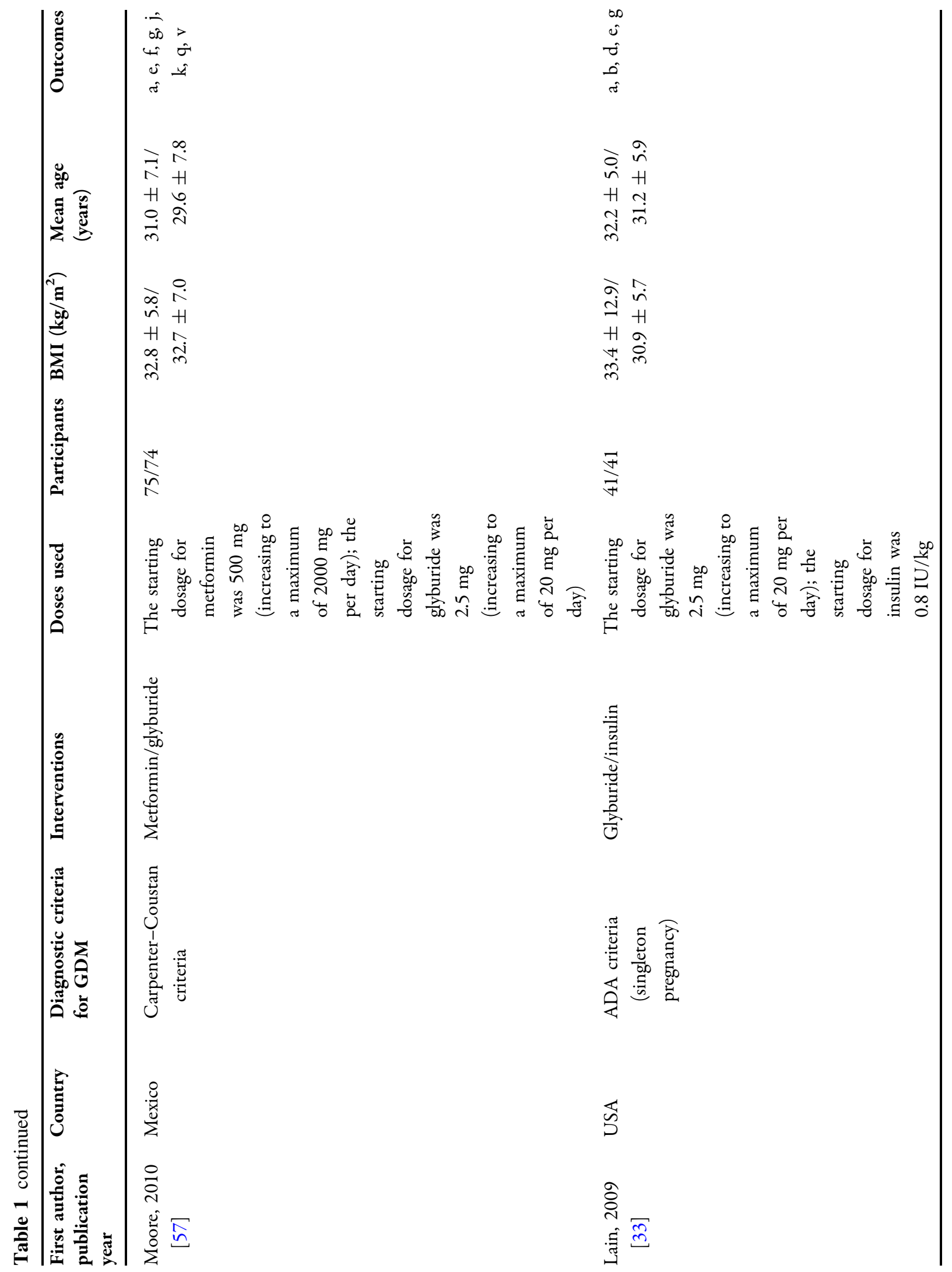




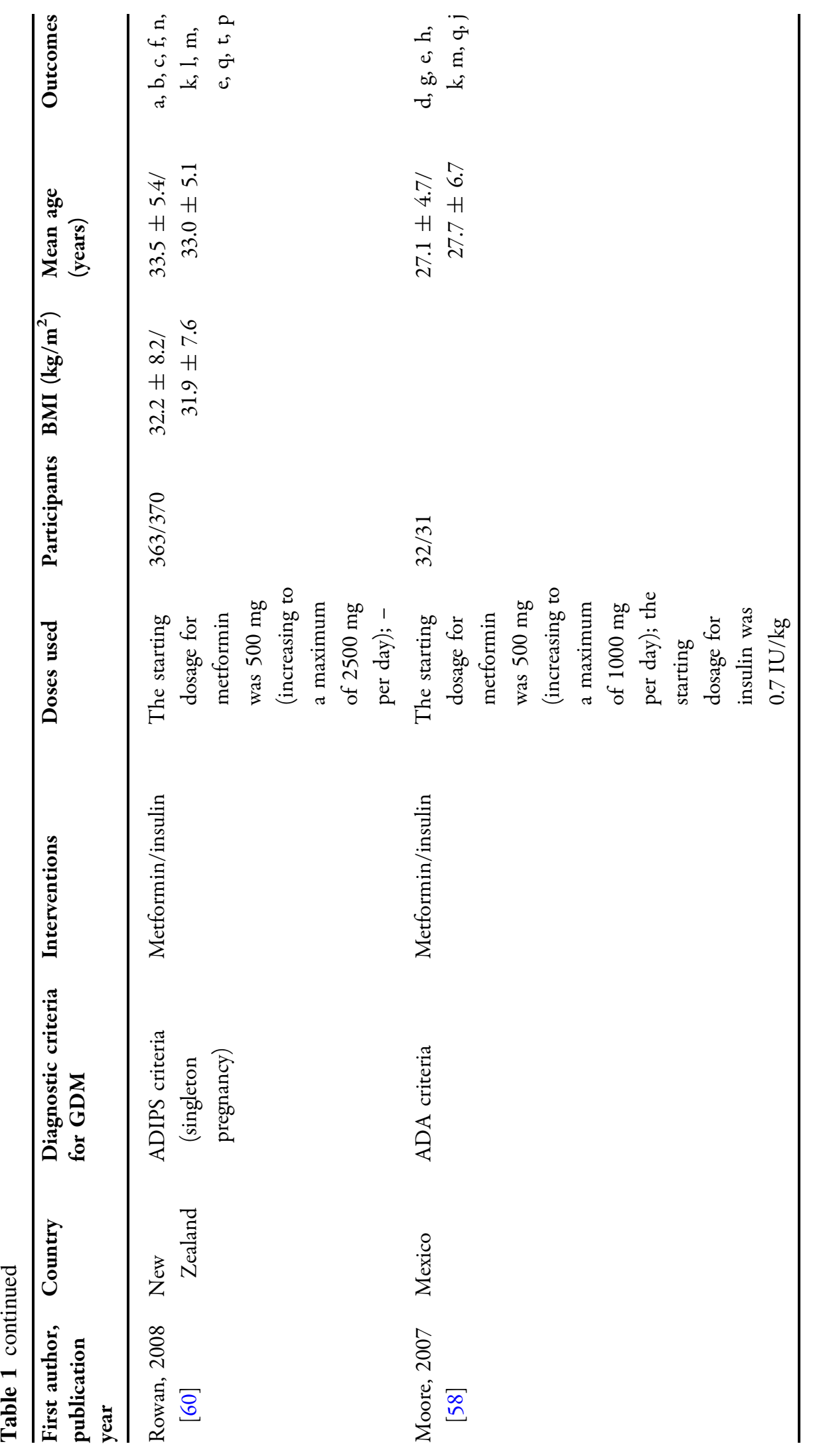




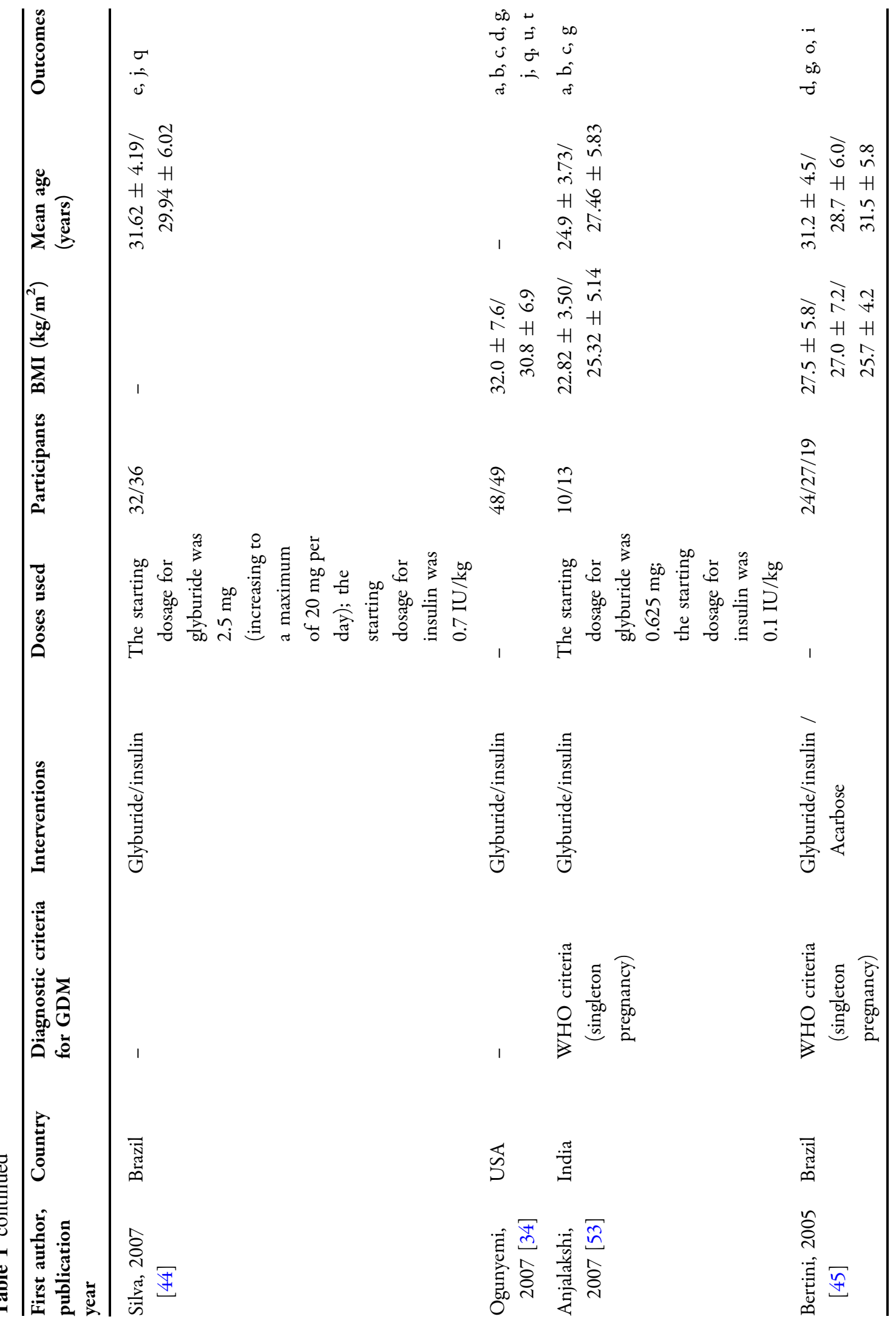




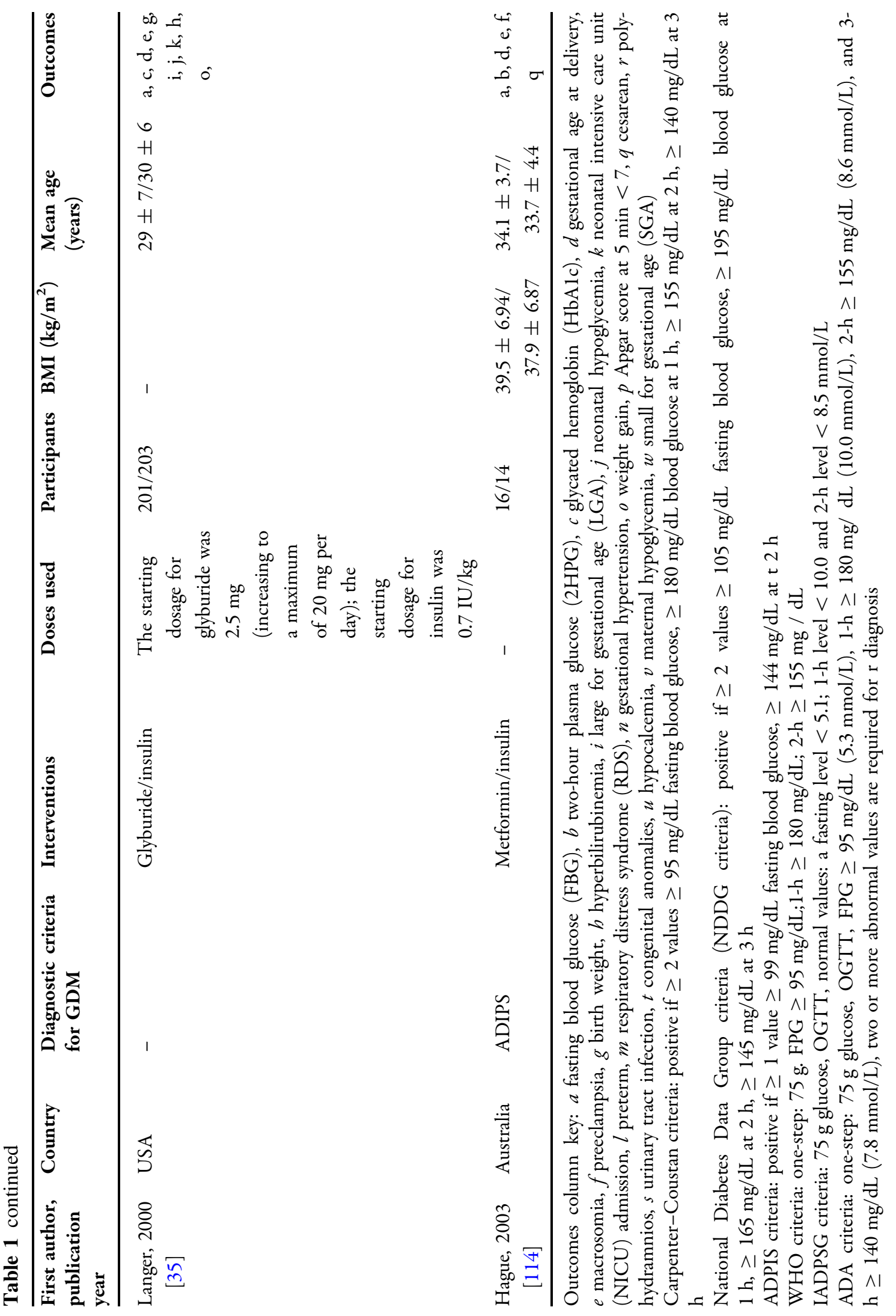


Organization standards, 5 adopted the ADA standards, 4 adopted the national standards (Carpenter-Coustan criteria), 3 used the Australasian Diabetes in Pregnancy standards, 1 used the National Diabetes Data Group standards, and 8 did not explicitly specify the diagnostic criteria applied.

Six interventions were reported in the studies: metformin, insulin, glyburide, acarbose, diet and exercise, and metformin plus insulin. Twenty-two studies investigated metformin vs. insulin (including clear maternal and infant outcome indicators), five investigated metformin vs. glyburide, ten investigated glyburide vs. insulin, two investigated diet and exercise vs. metformin vs. insulin, one investigated metformin vs. insulin vs. insulin + metformin, one investigated metformin vs. insulin + metformin, and one investigated glyburide vs. insulin vs. acarbose. The initial dose of metformin was $0.5-3 \mathrm{~g}$ per day; that of glyburide was 1.25-20 mg per day; and that of insulin was $0.1 \mathrm{IU} / \mathrm{kg}$, with the insulin dosage adjusted according to the blood glucose concentration.

\section{Quality Evaluation}

The quality of the included studies was evaluated, and the results showed that the blinding of the subjects and intervention providers was the main source of potential bias (Fig. 2). This was because blinding was not possible in trials that used insulin, as insulin and oral hypoglycemic agents are administered using completely different routes. Outcome evaluation blinding was a second source of potential bias. However, we believe that such bias was unlikely to have occurred since the main adverse maternal and infant outcomes in GDM were objectively defined, so the effect of outcome evaluation blinding by evaluators should have been limited. Incomplete outcome data was a third source of potential bias, which may have been due to discrepancies in the number and causes of missing outcome indicators between different groups.

\section{Network Evidence Diagram}

Figure 3 shows a network evidence diagram that includes the five interventions addressed in the NMA: metformin, insulin, glyburide, diet and exercise, and metformin + insulin. The size of the circles is proportional to sample size,the lines between circles represents direct comparative evidence and the width of the lines is proportional to the number of trials.

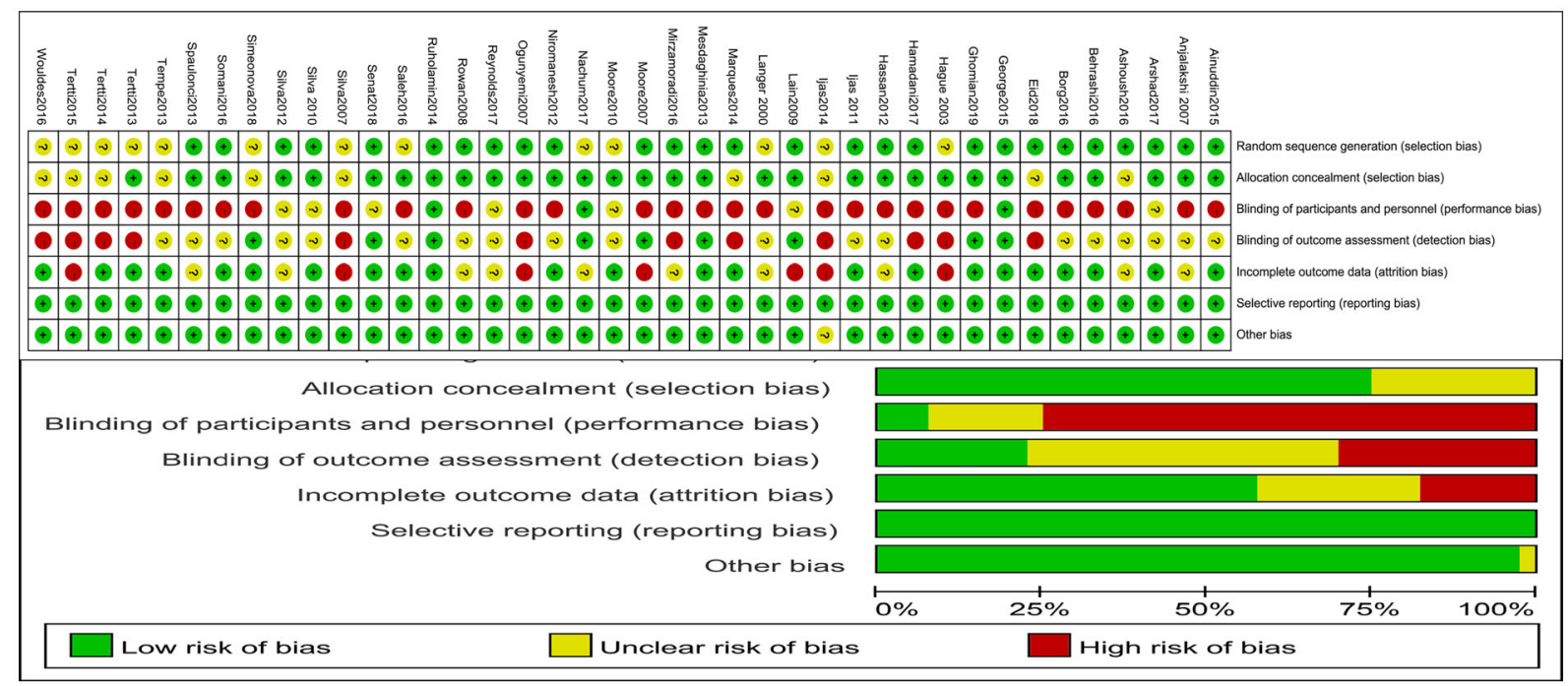

Fig. 2 Bias risk assessment of the RCTs 


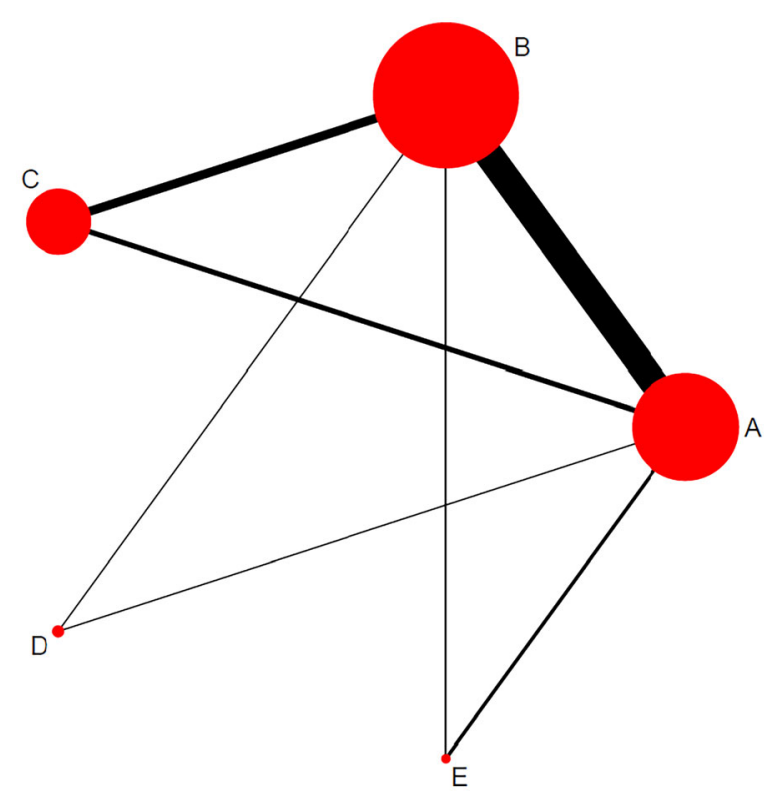

Fig. 3 Network plot of eligible comparisons between different glucose-lowering strategies. Interventions: $A$ metformin, $B$ insulin, $C$ glyburide, $D$ diet and exercise, $E$ metformin + insulin

\section{Direct Meta-analysis and Network Meta- analysis Results}

Table 2 shows the DMA and NMA results regarding neonatal and maternal outcomes. The analytical results for the different outcome indicators are described in the following sections.

\section{Infant Outcomes}

\section{Neonatal Intensive Care Unit (NICU) Admission}

Twenty-five studies involving 5097 GDM patients reported the impacts of different interventions on the incidence of NICU admission. In the DMA, we observed a higher incidence of NICU admission in the insulin group than in the metformin group (1.4, 95\% CI 1.1-1.8). No significant differences were observed between the remaining interventions. Similarly, in the NMA, we found a higher incidence of NICU admission in the insulin group $(1.3,95 \%$ CI 1.0-1.7) than in the metformin group, and no other significant differences between interventions were obtained.

\section{Neonatal Hypoglycemia}

Twenty-eight studies involving 4916 patients with GDM reported the effects of different interventions on neonatal hypoglycemia. In the DMA, we found a higher incidence in the insulin group than in the metformin group (1.6, 95\% CI 1.2-2.3). No significant differences between the remaining interventions were observed. In the NMA, we found a higher incidence of neonatal hypoglycemia in both the insulin (1.5, 95\% CI 1.1-2.1) and glyburide (2.0, 95\% CI 1.2-3.2) groups than in the metformin group, with no significant difference between the insulin and glyburide groups.

\section{Macrosomia}

Twenty-eight studies involving 4499 GDM patients reported the impacts of different interventions on the incidence of macrosomia in children. In both the DMA and NMA, none of the interventions were found to give a significant advantage in terms of reducing the incidence of macrosomia in children.

\section{Large for Gestational Age (LGA)}

Ten studies involving 1624 GDM patients reported the impacts of the interventions on LGA. In the DMA, none of the interventions provided a significant advantage in terms of the incidence of LGA. In the NMA, we found higher rates of LGA in both the insulin $(1.8,95 \%$ CI 1.0-3.3) and glyburide $(2.5,95 \%$ CI $1.1-8.4)$ groups than in the metformin group, with no significant difference between the insulin and glyburide groups. No other significant differences were observed between the remaining interventions.

\section{Preterm Birth}

Seventeen studies involving 3901 GDM patients reported the impacts of different interventions on the incidence of premature birth. In the DMA and NMA, we found no significant differences in prematurity between the metformin, insulin, glyburide, and diet and exercise groups. 
Table 2 Results of the DMA and NMA for neonatal and maternal outcomes

\begin{tabular}{|c|c|c|c|c|c|}
\hline \multirow[t]{2}{*}{ Outcome } & \multirow{2}{*}{$\begin{array}{l}\text { Studies } \\
(n)\end{array}$} & \multirow{2}{*}{$\begin{array}{l}\text { Participants } \\
(n)\end{array}$} & \multicolumn{2}{|l|}{ DMA } & \multirow{2}{*}{$\begin{array}{l}\text { NMA } \\
\text { Effect estimate }(95 \% \\
\text { CI) }\end{array}$} \\
\hline & & & $\begin{array}{l}\text { Effect estimate }(95 \% \\
\text { CI) }\end{array}$ & $\begin{array}{l}I^{2} \\
(\%)\end{array}$ & \\
\hline$N I C U$ & 25 & 5097 & & & \\
\hline Insulin vs. metformin & 16 & 2891 & $1.4(1.1,1.8)$ & $\mathbf{0}$ & $1.3(1.0,1.7)$ \\
\hline Glyburide vs. metformin & 3 & 421 & $0.50(0.20,1.2)$ & 5 & $0.89(0.55,1.4)$ \\
\hline Diet + exercise vs. metformin & 1 & 153 & $1.9(0.27,13.0)$ & - & $1.9(0.54,7.6)$ \\
\hline $\begin{array}{l}\text { Metformin }+ \text { insulin vs. } \\
\text { metformin }\end{array}$ & 2 & 107 & $2.5(0.50,13.0)$ & 66 & $1.3(0.45,3.4)$ \\
\hline Glyburide vs. insulin & 5 & 1727 & $0.84(0.50,1.4)$ & 0 & $0.68(0.43,1.1)$ \\
\hline Diet + exercise vs. insulin & 1 & 154 & $1.9(0.28,13.0)$ & - & $1.4(0.41,5.8)$ \\
\hline Metformin + insulin vs. insulin & 1 & 107 & $0.65(0.17,2.3)$ & 0 & $0.97(0.34,2.6)$ \\
\hline Neonatal bypoglycemia & 28 & 4916 & & & \\
\hline Insulin vs. metformin & 17 & 2403 & $1.6(1.2,2.3)$ & $\mathbf{0}$ & $1.5(1.1,2.1)$ \\
\hline Glyburide vs. metformin & 5 & 684 & $1.3(0.64,2.8)$ & 44 & $2.0(1.2,3.2)$ \\
\hline $\begin{array}{l}\text { Metformin }+ \text { insulin vs. } \\
\text { metformin }\end{array}$ & 1 & 75 & $3.2(0.078,4.7)$ & - & $1.1(0.24,4.4)$ \\
\hline Glyburide vs. insulin & 6 & 1796 & $1.6(0.94,2.7) 42$ & 42 & $1.3(0.82,2.0)$ \\
\hline Metformin + insulin vs. insulin & 1 & 107 & $0.48(0.10,2.2)$ & - & $0.70(0.15,2.8)$ \\
\hline Macrosomia & 28 & 4949 & & & \\
\hline Insulin vs. metformin & 15 & 2487 & $1.7(0.93,3.2)$ & 36 & $1.5(0.89,2.6)$ \\
\hline Glyburide vs. metformin & 4 & 484 & $1.5(0.43,5.4)$ & 14 & $1.8(0.89,4.1)$ \\
\hline Diet + exercise vs. metformin & 1 & 153 & $1.2(0.046,31.0)$ & - & $2.7(0.19,96.0)$ \\
\hline $\begin{array}{l}\text { Metformin }+ \text { insulin vs. } \\
\text { metformin }\end{array}$ & 2 & 79 & $3.2(0.44,28.0)$ & 53 & $3.1(0.45,24.0)$ \\
\hline Glyburide vs. insulin & 7 & 1877 & $1.3(0.62,3.3)$ & 70 & $1.2(0.64,2.5)$ \\
\hline Diet + exercise vs. insulin & 1 & 154 & - & - & $1.8(0.13,63.0)$ \\
\hline$L G A$ & 10 & 1624 & & & \\
\hline Insulin vs. metformin & 6 & 751 & $1.6(0.77,3.4)$ & 0 & $1.8(1.0,3.3)$ \\
\hline Glyburide vs. metformin & 1 & 72 & $3.0(0.51,23.0)$ & & $2.5(1.1,8.4)$ \\
\hline Diet + exercise vs. metformin & 2 & 401 & $3.1(0.76,13.0)$ & 0 & $2.4(0.92,6.0)$ \\
\hline $\begin{array}{l}\text { Metformin }+ \text { insulin vs. } \\
\text { metformin }\end{array}$ & 2 & 122 & $2.6(0.57,13.0)$ & 44 & $1.7(0.59,5.7)$ \\
\hline Glyburide vs. insulin & 2 & 453 & $1.4(0.58,5.9)$ & 79 & $1.4(0.67,4.2)$ \\
\hline Diet + exercise vs. insulin & 2 & 455 & $1.3(0.39,3.4)$ & 0 & $1.3(0.53,3.1)$ \\
\hline
\end{tabular}


Table 2 continued

\begin{tabular}{|c|c|c|c|c|c|}
\hline \multirow[t]{2}{*}{ Outcome } & \multirow{2}{*}{$\begin{array}{l}\text { Studies } \\
(n)\end{array}$} & \multirow{2}{*}{$\begin{array}{l}\text { Participants } \\
(n)\end{array}$} & \multicolumn{2}{|l|}{ DMA } & \multirow{2}{*}{$\begin{array}{l}\text { NMA } \\
\text { Effect estimate }(95 \% \\
\text { CI) }\end{array}$} \\
\hline & & & $\begin{array}{l}\text { Effect estimate }(95 \% \\
\text { CI) }\end{array}$ & $\begin{array}{l}I^{2} \\
(\%)\end{array}$ & \\
\hline Metformin + insulin vs. insulin & 1 & 1107 & $0.64(0.13,3.1)$ & - & $0.94(0.33,3.2)$ \\
\hline Preterm birth & 17 & 3901 & & & \\
\hline Insulin vs. metformin & 12 & 2307 & $1.4(0.77,3.4)$ & 42 & $1.4(0.75,3.1)$ \\
\hline Glyburide vs. metformin & 2 & 263 & $0.45(0.069,2.6)$ & 0 & $1.0(0.26,3.6)$ \\
\hline Diet + exercise vs. metformin & 2 & 401 & $1.8(0.27,11.0)$ & 0 & $0.91(0.25,4.3)$ \\
\hline Glyburide vs. insulin & 2 & 978 & $1.3(0.26,6.1)$ & 0 & $0.73(0.17,2.3)$ \\
\hline Diet + exercise vs. insulin & 2 & 455 & $0.45(0.11,2.1)$ & 64 & $0.65(0.17,2.7)$ \\
\hline$R D S$ & 15 & 3478 & & & \\
\hline Insulin vs. metformin & 11 & 2060 & $1.3(0.75,2.2)$ & 0 & $1.3(0.82,2.2)$ \\
\hline Glyburide vs. metformin & 1 & 159 & $2.2(0.33,21.0)$ & 0 & $1.1(0.46,2.6)$ \\
\hline $\begin{array}{l}\text { Metformin }+ \text { insulin vs. } \\
\text { metformin }\end{array}$ & 1 & 75 & $3.6(0.045,4.8)$ & - & $2.1(0.23,15.0)$ \\
\hline Glyburide vs. insulin & 3 & 1227 & $0.73(0.29,1.7) 0$ & 0 & $0.82(0.38,1.8)$ \\
\hline Metformin + insulin vs. insulin & 1 & 107 & $1.4(0.14,15.0)$ & - & $1.6(0.18,11.0)$ \\
\hline Cesarean section & 25 & 4386 & & & \\
\hline Insulin vs. metformin & 16 & 2374 & $1.1(0.89,1.4)$ & 26 & $1.1(0.88,1.3)$ \\
\hline Glyburide vs. metformin & 4 & 484 & $0.71(0.43,1.2)$ & 37 & $0.76(0.55,1.0)$ \\
\hline Diet + exercise vs. metformin & 2 & 401 & $0.62(0.32,1.2)$ & 0 & $0.75(0.48,1.2)$ \\
\hline $\begin{array}{l}\text { Metformin + insulin vs. } \\
\text { metformin }\end{array}$ & 1 & 32 & $2.2(0.44,11.0)$ & - & $2.2(0.45,11.0)$ \\
\hline Glyburide vs. insulin & 4 & 1175 & $0.74(0.50,1.1)$ & 0 & $0.71(0.52,0.96)$ \\
\hline Diet + exercise vs. insulin & 2 & 455 & $0.80(0.45,1.5)$ & 0 & $0.70(0.45,1.1)$ \\
\hline Gestational hypertension & 8 & 1852 & & & \\
\hline Insulin vs. metformin & 6 & 1577 & $1.4(0.88,2.6)$ & 0 & $1.4(0.89,2.5)$ \\
\hline Glyburide vs. metformin & 2 & 263 & $1.6(0.58,5.1)$ & 0 & $1.6(0.60,5)$. \\
\hline $\begin{array}{l}\text { Metformin }+ \text { insulin vs. } \\
\text { metformin }\end{array}$ & 1 & 75 & $0.39(0.031,5.1)$ & - & $0.43(0.078,1.8)$ \\
\hline Metformin + insulin vs. insulin & 1 & 107 & $0.28(0.046,1.7)$ & - & $0.30(0.054,1.2)$ \\
\hline Preeclampsia & 14 & 2612 & & & \\
\hline Insulin vs. metformin & 11 & 1894 & $1.2(0.73,2.1)$ & 0 & $1.3(0.82,2.4)$ \\
\hline Glyburide vs. metformin & 1 & 149 & $1.7(0.22,13)$. & 0 & $1.9(0.49,8.3)$ \\
\hline
\end{tabular}


Table 2 continued

\begin{tabular}{|c|c|c|c|c|c|}
\hline \multirow[t]{2}{*}{ Outcome } & \multirow{2}{*}{$\begin{array}{l}\text { Studies } \\
(n)\end{array}$} & \multirow{2}{*}{$\begin{array}{l}\text { Participants } \\
\text { (n) }\end{array}$} & \multicolumn{2}{|l|}{ DMA } & \multirow{2}{*}{$\begin{array}{l}\text { NMA } \\
\text { Effect estimate (95\% } \\
\text { CI) }\end{array}$} \\
\hline & & & $\begin{array}{l}\text { Effect estimate (95\% } \\
\text { CI) }\end{array}$ & $\begin{array}{l}I^{2} \\
(\%)\end{array}$ & \\
\hline Diet + exercise vs. metformin & 2 & 401 & $0.21(0.024,1.9)$ & 0 & $0.19(0.043,0.72)$ \\
\hline $\begin{array}{l}\text { Metformin }+ \text { insulin vs. } \\
\text { metformin }\end{array}$ & 2 & 107 & $0.95(0.13,6.4)$ & 0 & $0.58(0.16,1.9)$ \\
\hline Glyburide vs. insulin & 1 & 64 & $1.7(0.40,7.1)$ & - & $1.5(0.37,5.9)$ \\
\hline Diet + exercise vs. insulin & 2 & 455 & $0.20(0.025,1.7)$ & 7 & $0.15(0.032,0.52)$ \\
\hline Metformin + insulin vs. insulin & 1 & 107 & $0.22(0.013,4.0)$ & - & $0.76(0.085,4.6)$ \\
\hline
\end{tabular}

\section{Respiratory Distress Syndrome (RDS)}

Fifteen studies involving 3478 GDM patients reported the impacts of the interventions on RDS. We found that none of the interventions provided a significant advantage in terms of the incidence of RDS in either the DMA or the NMA.

\section{Maternal Outcomes}

\section{Cesarean Section}

Twenty-five studies reported the effects of different interventions on cesarean section incidence in pregnant women with GDM. In the DMA, there was no significant difference in incidence between the interventions. In the NMA, we found the probability of cesarean section in the glyburide group to be significantly lower than those in the metformin $(0.76$, 95\% CI 0.55-1.0) and insulin (0.71, 95\% CI $0.52-0.96)$ groups. No significant differences between the metformin, insulin, metformin + insulin, and diet and exercise groups were observed.

\section{Gestational Hypertension}

Eight studies involving 1852 GDM patients reported the impacts of the interventions on gestational hypertension. We found that none of the interventions provided a significant advantage in terms of the incidence of gestational hypertension in either the DMA or the NMA.

\section{Preeclampsia}

Fourteen studies involving 2612 GDM patients reported the impacts of the GDM treatments on the incidence of preeclampsia. We observed no significant differences between the different interventions in the DMA. In the NMA, the preeclampsia risk was significantly lower in the metformin (0.19, 95\% CI 0.043-0.72) and insulin $(0.15,95 \%$ CI $0.032-0.52)$ groups. No significant differences between the metformin, insulin, glyburide, and metformin + insulin groups were observed.

\section{SUCRA}

NMA can evaluate the best effect of each intervention for different results and sort the interventions by SUCRA value, with a higher SUCRA value indicating a better intervention or a lower incidence of adverse reactions. Table 3 displays the detailed ranking results. According to Table 3, the metformin group had the lowest incidences of neonatal hypoglycemia (84.2\%), macrosomia (88.5\%), LGA (94.3\%), and RDS (74.5\%). The glyburide group had the lowest incidences of NICU admission (81.9\%) and cesarean section $(82.8 \%)$ and the highest incidences of neonatal hypoglycemia (10.3\%), LGA 


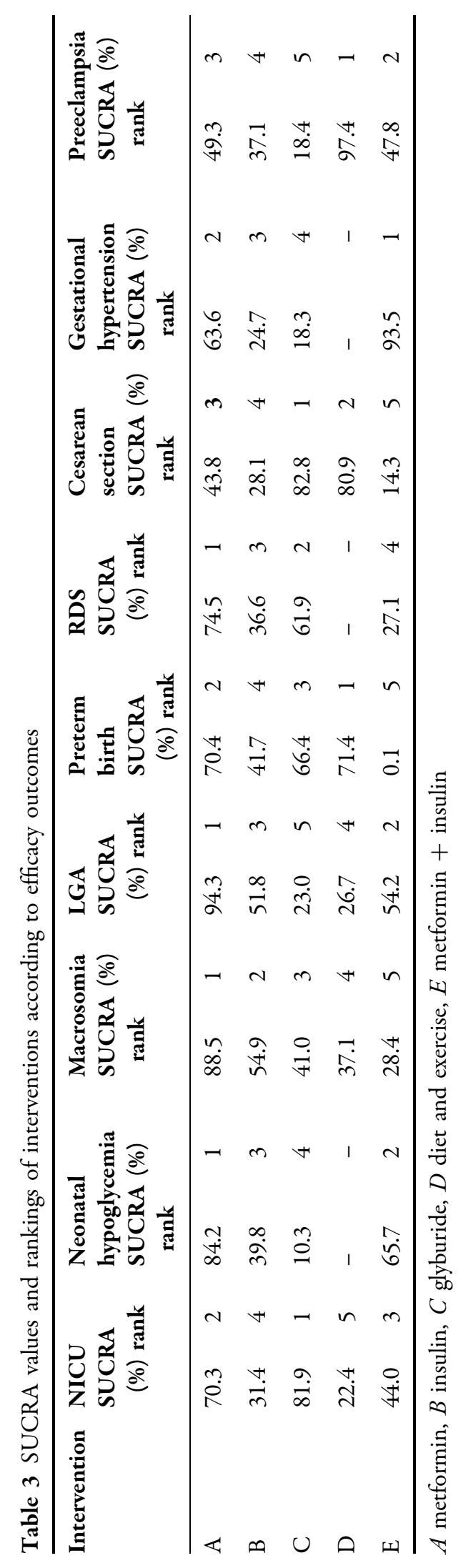


(23.0\%), preeclampsia (18.4\%), and gestational hypertension (18.3\%). The diet and exercise group had the lowest incidences of preterm birth (71.4\%) and preeclampsia (97.4\%) and the highest incidence of NICU admission (22.4\%). Furthermore, we found that in the metformin + insulin group, the incidences of macrosomia, preterm birth, RDS, cesarean section, NICU admission, neonatal hypoglycemia, and LGA were higher than those in the metformin-only group and lower than those in the insulin-only group. However, the incidences of preeclampsia and gestational hypertension in the metformin + insulin group were lower than those in the metformin and insulin groups.

\section{Publication Bias}

Figure 4 displays a comparison-adjusted funnel diagram. All studies on the funnel map are symmetrically distributed with respect to the vertical line $X=0$, indicating that there were no significant small-sample effects or publication bias.

\section{DISCUSSION}

GDM is a particular type of diabetes that has short- and long-term impacts on pregnant women with GDM and their offspring.

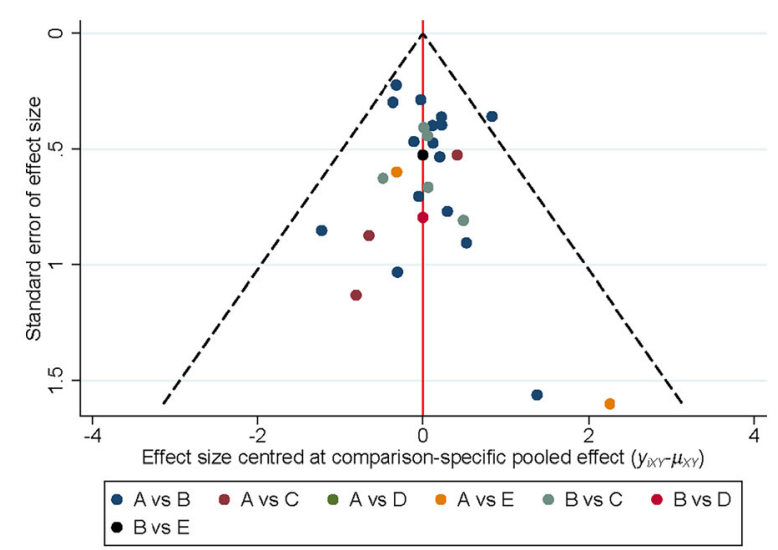

Fig. 4 Comparison-adjusted funnel plot. Points with different colors represent different interventions. Interventions: $A$ metformin, $B$ insulin, $C$ glyburide, $D$ diet and exercise, $E$ metformin + insulin
Therefore, blood glucose control in pregnant women with GDM is crucial. In addition to diet, exercise, and subcutaneous insulin injection, oral hypoglycemic drugs (mainly metformin and glyburide) are also increasingly used to control blood glucose in pregnant women with GDM. A few studies have investigated acarbose as a GDM treatment, but we identified only one RCT on the application of acarbose in GDM treatment (conducted by Bertini [44]). Due to its small sample size, its use of just a few study outcome indicators, its long duration, and the lack of other RCTs with larger sample sizes to further reduce the heterogeneity in the NMA, we excluded this study from our network metaanalysis.

Several studies have compared the abovementioned treatments to analyze their impacts on maternal and infant outcomes for pregnant women with GDM and thus assess their efficacies and safety. However, DMA has mainly been used to compare the effects of two different interventions, and few studies have compared the effects of multiple different glucose-reduction measures. Therefore, we identified relevant published RCTs and applied NMA to perform direct and indirect comparisons of maternal and infant outcomes in women with GDM (the infant outcomes included neonatal hypoglycemia, macrosomia, RDS, NICU admission, LGA, and preterm delivery, while the maternal outcomes included gestational hypertension, preeclampsia, and cesarean section). The NMA was designed to elucidate the risks and benefits of different treatment options to aid clinicians when they are selecting GDM treatment strategies.

Metformin, a small molecule, is an oral hypoglycemic agent that can improve insulin sensitivity, reduce heterogeneous products of liver glycogen, and enhance peripheral glucose intake, thus reducing blood glucose [64]. Metformin also stimulates the release of glucagonlike peptide 1, thereby enhancing insulin secretion [65]. A study by Eyal et al. [66] found that metformin concentrations in umbilical cord blood could even reach maternal levels, suggesting an ability of metformin to pass through the placental barrier. Therefore, safety issues regarding metformin application during 
pregnancy have attracted considerable attention. Landi et al. [67] conducted a retrospective cohort study in which metformin treatment did not increase the risks of adverse maternal or neonatal outcomes. However, opinions regarding the effect of metformin for GDM on maternal and infant outcomes vary. In our study, both DMA and NMA demonstrated that metformin reduced the incidences of neonatal hypoglycemia and NICU admission compared to insulin, and SUCRA sequencing found that the incidence of neonatal hypoglycemia was lowest in the metformin group, consistent with a previous meta-analysis by Wang et al. [68-72]. Since glucose can pass through the placenta, high maternal blood glucose leads to increased fetal glucose levels, resulting in excessive insulin secretion in the fetus. Even though the mother stops providing glucose after birth, neonatal insulin levels remain high, predisposing the newborn to neonatal hypoglycemia [73]. Studies have found that metformin can better control blood glucose [74] during pregnancy than insulin, and that it potentially reduces the occurrence of neonatal hypoglycemia to some extent. Neonatal hypoglycemia is also one of the diagnoses most commonly used to determine whether newborns require admission to the NICU. Thus, metformin reduces the incidence of neonatal hypoglycemia and reduces NICU occupancy to some extent. Relevant randomized incidences of LGA in previous cohort studies $[40,48,75,76]$ suggest that metformin does not statistically significantly reduce LGA incidence. For example, Ainuddin et al. [48] compared groups treated with metformin, metformin + insulin, and insulin, and found no statistically significant difference in LGA incidence between the three groups. However, several recent meta-analyses suggest that metformin reduces LGA incidence compared to insulin therapy for GDM [68-70, 77, 78]. In our NMA, we also found that the insulin group had a higher LGA incidence than the metformin group. SUCRA sequencing results also showed that the metformin group had the lowest LGA incidence, followed by the metformin + insulin and insulin groups, with the highest incidence observed in the glyburide group. A study by $\mathrm{Yu}$ on dynamic blood glucose monitoring revealed that metformin therapy can better control blood glucose in pregnant women, thus reducing the incidence of LGA to a certain extent [79]. DMA and NMA data regarding the incidences of macrosomia, preterm birth, RDS, gestational hypertension, preeclampsia, and cesarean section suggest that there is no significant difference between the metformin and insulin groups regarding these incidences. This is consistent with the findings of Bao et al. $[70,80]$. Their meta-analysis results also suggested that there is no statistically significant difference between the metformin and insulin treatments in the probabilities of gestational hypertension, preeclampsia, and cesarean section in pregnant women with GDM. However, Tarry et al. [80] suggested that metformin increases the risk of macrosomia in offspring, whereas the study by Wang et al. produced conflicting results. Their results suggest that metformin can reduce the incidences of macrosomia, cesarean section, and gestational hypertension compared with insulin treatment in pregnant women with GDM $[68,69]$. The main reason behind the differences between the results of the analyses may be that the inclusion and exclusion criteria applied were inconsistent across studies, leading to certain differences between the data in the included literature and, in turn, to differing research results.

Glyburide is a second-generation sulfonylurea hypoglycemic agent that stimulates insulin release by binding to the sulfonylurea receptor on the islet B-cells to reduce blood glucose.It can also enhance the sensitivity of surrounding tissue to insulin, thus reducing blood glucose. There is no unified conclusion regarding the effect of glyburide on maternal and infant outcomes in pregnant women with GDM. In 2019, a meta-analysis conducted by Guo et al. [69] suggested that neonatal hypoglycemia was more common with GDM patients receiving glyburide than with those receiving insulin, which is consistent with the study findings of Poolsup et al. [81, 82]. Jiang et al. also found that a glyburide group was more prone to macrosomia. However, this was not consistent with findings of Amin et al. [83]. Amin et al. found that glyburide did not 
increase the incidences of preterm birth, neonatal hypoglycemia, and macrosomia. In our NMA, we found that the glyburide group was more likely to develop neonatal hypoglycemia and LGA than the metformin group, while no statistically significant differences in NICU admission, macrosomia, preterm birth, RDS, and gestational hypertension were observed. SUCRA sequencing results also showed that the metformin group had the lowest incidences of neonatal hypoglycemia and LGA, while the glyburide group had the highest incidence. Hebert et al. [84] completed a study on the pharmacokinetics and pharmacodynamics of glyburide in women with GDM in 2009 and demonstrated that glyburide use during pregnancy increased the concentration of the drug in umbilical cord blood in the GDM group. Furthermore, Melamed et al. [85] asserted that there was insufficient data on the safety of placental transfer during glyburide treatment of GDM in pregnant women in early pregnancy, and there were reports of increased neonatal morbidity. This seems to explain the apparent association between glyburide and an increased incidence of neonatal hypoglycemia. The main effect of glyburide is to increase insulin secretion, thereby reducing glucose production in the liver and indirectly improving insulin sensitivity [86]. It enters the fetus through placental transfer, subsequently causing excessive insulin secretion in the fetus and potentially leading to severe post-birth hypoglycemia in the newborn. Through DMA and NMA, we found the incidence of cesarean section in the glyburide group to be significantly lower than those in the metformin and insulin groups, while no significant difference in cesarean section incidence was observed between the insulin, metformin, and diet groups. SUCRA sequencing results also showed that the glyburide group had the lowest incidence of cesarean section, while the metformin + insulin group had the highest incidence. In the NMA and DMA, no significant statistically significant differences between the glyburide and other groups in NICU admission, macrosomia, preterm birth, RDS, gestational hypertension, and other aspects were observed. Although no statistically significant differences in NICU admission, macrosomia, premature birth, RDS, and gestational hypertension were observed between the glyburide group and the metformin and insulin groups, glyburide was observed to reduce cesarean section incidence. However, it potentially increases the incidence of neonatal hypoglycemia, and a diagnosis of neonatal hypoglycemia is commonly used to determine whether a newborn requires NICU admission. Therefore, the clinical feasibility, advantages, and disadvantages of glyburide require further confirmation in future RCTs with larger sample sizes. Furthermore, caution should be exercised when selecting glyburide to treat GDM.

OADs (mainly metformin and glyburide) can also elicit other adverse reactions during pregnancy in addition to the general outcomes of pregnant women with GDM. The most common adverse reactions associated with metformin are gastrointestinal symptoms, such as nausea, vomiting, and diarrhea. Such adverse effects decrease over time and are potentially reduced by decreasing the dose and taking metformin with food [87]. The most serious adverse reaction is metformin-associated lactic acidosis; however, this is rare in patients with normal liver and kidney function, with only 3 per 100,000 patients affected during metformin use. Other less common side effects include a change in taste, elevated liver enzymes, and skin erythema or urticaria [88]. The main side effect of glyburide is hypoglycemia; others include gastrointestinal symptoms and headache, individual patients can suffer from skin allergies, and reversible changes in the hematopoietic system are occasionally reported $[89,90]$.

Among the several interventions available, diet and exercise is a special intervention. A diet and exercise group is generally considered a good control group for assessing the efficacy and safety of metformin in GDM treatment. In several previous observational studies, Balani et al. [75, 91, 92] found the incidences of neonatal hypoglycemia, macrosomia, LGA, cesarean section, and preterm delivery to be higher in pregnant women with GDM treated through diet and exercise than in those treated with metformin. However, in a study by Tertti 
et al. [76], no statistically significant differences in neonatal weight, macrosomia, LGA, etc. between a diet and exercise group and metformin and insulin groups were observed. In our DMA and NMA, we found the risks of developing preeclampsia and gestational hypertension to be significantly lower in the diet and exercise group than in the metformin and insulin groups, while no other significant differences were noted. SUCRA ranking also demonstrated that the diet and exercise group had the lowest incidence of preeclampsia and the highest incidence of NICU occupancy. On further analysis, we found that this result might have been due to the effects of diet and exercise on weight during pregnancy. On the one hand, strict diabetes-related diet control and daily caloric intake limitation potentially mitigate weight gain during pregnancy to a certain extent. On the other hand, exercise enhances the absorption of circulating blood glucose in muscle tissue. In addition, it increases the translocation of the insulin-reactive glucose transporter GLUT4 from intracellular storage to the cell surface, thus further promoting glucose intake and reducing weight gain during pregnancy $[93,94]$. Relevant studies have found that excessive adipose tissue can affect the production of adipokines, driving factors, and cytokines, which interact with autocrine and paracrine networks [95-97], thus potentially leading to vascular endothelial cell damage and increased the incidences of gestational hypertension and preeclampsia. Furthermore, the study found that overweight or obese women showed increased insulin resistance during pregnancy, which worsened as pregnancy progressed [20], thus leading to increased blood pressure. Diet and exercise can reduce weight gain during pregnancy, insulin resistance to some extent, and the incidences of gestational hypertension and preeclampsia. However, we included only two RCTs on diet and exercise, which provided minimal data. And diet and exercise is a common intervention for GDM, although the diet used and exercise performed can vary.

In addition to the effects of OADs (metformin, glyburide), insulin, and diet and exercise, as discussed above, the role of vitamin D in gestational diabetes has increasingly been studied in recent years. In 2017, Karoline systematically reviewed the physiological role of vitamin $\mathrm{D}$ during pregnancy, the incidence of vitamin D deficiency during pregnancy, and its effects on pregnancy-related disorders and offspring outcomes [98]. The review noted that low vitamin D levels in pregnant women are associated with higher risks of preeclampsia, gestational diabetes, and other conditions of pregnancy, as well as a number of other negative effects, including fetal growth restriction, an increased risk of preterm birth, and altered susceptibility to diseases later in life [98]. In 2020, a meta-analysis by Wang et al. found that vitamin $D$ deficiency was associated with a higher risk of GDM and negatively associated with homeostasis model assessment-insulin resistance index (HOMA-IR) [99], which is consistent with the findings of Rajesh and Xia [100-102]. Those studies suggest that vitamin D deficiency may increase the risk of GDM, and that supplementation during pregnancy may improve GDM [100-102]. In another metaanalysis, Wang et al. found that vitamin D supplementation significantly reduced serum fasting glucose (FPG) and HOMA-IR in women with GDM [103]. At the same time, vitamin D supplementation in pregnant women with GDM can significantly reduce adverse maternal outcomes, including cesarean section and postpartum bleeding, and severe neonatal complications, including neonatal hyperbilirubinemia, macrosomia, fetal distress, and preterm birth [103]. The effect of vitamin D on the incidence of GDM and related pregnancy outcomes may be closely related to its ability to reduce insulin resistance in pregnant women. The results of relevant meta-analyses all suggest that vitamin $\mathrm{D}$ can effectively reduce insulin resistance [99, 103]. In 2021, Chen et al. also found a negative association between vitamin $\mathrm{D}$ and insulin resistance in women with vitamin $\mathrm{D}$ deficiency, while the association was not significant in men with vitamin $D$ deficiency [104]. However, the conclusion that vitamin D has positive effects on the incidence of GDM and the pregnancy outcomes of GDM pregnant women has not been unanimously accepted. Relevant studies have found no significant 
correlation of vitamin D deficiency with the incidence of GDM and adverse pregnancy outcomes [105-108]. Therefore, more randomized controlled trials are needed to check whether pregnant women with GDM should actively take vitamin D supplements during pregnancy. The studies discussed above also show that in the future, GDM treatments should not only consider the selection of appropriate hypoglycemic drugs but should also pay attention to the relevant role of vitamin D in GDM.

Another issue that deserves our attention is how many of the women with GDM included in our study conceived through in vitro fertilization (IVF) rather than naturally. In 2014, a study identified assisted reproductive technology (ART) as an important risk factor for GDM, finding that single-pregnancy women who underwent ART were twice as likely to develop GDM as women who conceived naturally [109]. In 2020, a meta-analysis also confirmed that women who obtained singleton pregnancies using ATR had a higher risk of GDM compared to women who obtained singleton pregnancies spontaneously [110]. At the same time, studies have found that ART increases the risk of adverse maternal and infant outcomes, such as hypertension during pregnancy, intrahepatic cholestasis, placental abruption, premature rupture of membranes, postpartum hemorrhage, preterm birth, and low birth weight [111-113]. Therefore, when exploring the effects of different hypoglycemic measures on the pregnancy outcomes of pregnant women with GDM, we should conduct a stratified analysis of the pregnancy patterns of those women so as to exclude the effects caused by different pregnancy patterns. However, when we extracted the data, we found that most of the women included in the study had single pregnancies but it was not clear whether they conceived naturally or through ART. This is a limitation of our study. Therefore, in the future, we need to conduct more randomized controlled trials to further explore the role of hypoglycemic drugs in pregnant women with GDM who conceived naturally and in those who conceived through ART.

A particular advantage of NMA is its ability to estimate the effects of different interventions by combining direct and circumstantial evidence. Therefore, we compared the different GDM treatments using NMA, rather than performing separate meta-analyses of individual treatments, thus increasing the accuracy of the estimates. Our study, which involved a comprehensive analysis of the current main treatment methods for GDM, incorporated the latest RCTs and sorted the various treatment results, meaning that our results provide a detailed and reliable basis for clinicians to select GDM treatment options.

However, our study has certain limitations. First, there there were differences between the studies included in our meta-analysis in race, background, and age. Since the ages of the pregnant women with GDM we included were all around the average age of a pregnant woman, it was difficult to perform age stratification. Therefore, a randomized controlled trial involving a larger area and a larger population is required to perform further analysis. Second, while we focused on pregnant women with GDM, different studies included in the metaanalysis used different diagnostic criteria for GDM. Third, because insulin and oral hypoglycemic drugs are administered via completely different routes, blinding was impossible, which was also the main reason for potential bias. As for the second cause of potential bias-outcome evaluation blindness, we believe that since the main adverse maternal and infant outcomes in GDM were objectively defined, such bias was unlikely to have occurred; therefore, the effect of outcome evaluation on outcome blindness by evaluators should have been limited. Fourth, differences in administration protocol, types and doses of drugs, and intervention time between the studies may have affected the clinical efficacy. Finally, some research methods have limitations, and the units of the evaluation indicators differ. However, the conclusions and limitations of this study may facilitate the design of new trials.

\section{CONCLUSION}

In summary, our findings suggest that metformin is associated with minimal incidences of 
multiple adverse outcome indicators and does not lead to high values of certain adverse outcome indices. Although the glyburide group had the lowest rates of NICU occupancy and cesarean section, it had the highest rates of neonatal hypoglycemia, large for gestational age newborns, preeclampsia, and gestational hypertension. Therefore, more attention should be directed to glyburide-related adverse effects in pregnant women with GDM. Moreover, we found that although the insulin + metformin group had lower incidences of preeclampsia and gestational hypertension than the metforminonly group, it also had the highest incidences of multiple adverse outcomes. Therefore, when selecting a GDM treatment strategy, the efficacies and risks of the different treatment programs should be evaluated according to the scenario in hand.

\section{ACKNOWLEDGEMENTS}

We gratefully acknowledge Junwu Wang for providing intellectual support and technical assistance.

Funding. The journal's Rapid Service Fee was funded by Shengjing Hospital of China Medical University. This research was supported by the National Natural Science Foundation of China (No. 81700706), the 345 Talent Project of Shengjing hospital, the Clinical research project of Liaoning Diabetes Medical Nutrition Prevention Society (No. LNSTNBYXYYFZXHRS01B), the Science Foundation of Liaoning Education Department (No. LK201603), and the Virtual simulation experiment teaching project of China Medical University (No. 2020-47).

Authorship. All named authors meet the International Committee of Medical Journal Editors (ICMJE) criteria for authorship for this article, take responsibility for the integrity of the work as a whole, and have given their approval for this version to be published.

Author Contributions. H OY collected material and wrote the manuscript. NW helped with the discussion, supervised the work and provided critical feedback. All authors made substantial contributions to conception and design, took part in drafting the article or revising it critically for important intellectual content; gave final approval of the version to be published; and agree to be accountable for all aspects of the work.

Disclosures. Hong Ouyang and $\mathrm{Na} \mathrm{Wu}$ declare that they have nothing to disclose.

Compliance with Ethics Guidelines. This article is based on previously conducted studies and does not contain any new studies with human participants or animals performed by any of the authors and therefore ethical approval was not required.

Data Availability. All data generated or analyzed during this study are included in this published article.

Open Access. This article is licensed under a Creative Commons Attribution-NonCommercial 4.0 International License, which permits any non-commercial use, sharing, adaptation, distribution and reproduction in any medium or format, as long as you give appropriate credit to the original author(s) and the source, provide a link to the Creative Commons licence, and indicate if changes were made. The images or other third party material in this article are included in the article's Creative Commons licence, unless indicated otherwise in a credit line to the material. If material is not included in the article's Creative Commons licence and your intended use is not permitted by statutory regulation or exceeds the permitted use, you will need to obtain permission directly from the copyright holder. To view a copy of this licence, visit http://creativecommons.org/licenses/by$\mathrm{nc} / 4.0 /$.

\section{REFERENCES}

1. Ehrlich SF, Sternfeld B, Krefman AE, Hedderson MM, Brown SD, Mevi A, Chasan Taber L, Quesenberry CP Jr, Ferrara A. Erratum to: moderate and 
vigorous intensity exercise during pregnancy and gestational weight gain in women with gestational diabetes. Matern Child Health J. 2016;20(9): 1989-92. https://doi.org/10.1007/s10995-016-20198.

2. Brown J, Ceysens G, Boulvain M. Exercise for pregnant women with gestational diabetes for improving maternal and fetal outcomes. Cochrane Database Syst Rev. 2017;6(6):CD012202. https:// doi.org/10.1002/14651858.

3. Association TAD. Diagnosis and classification of diabetes mellitus. Diabetes Care. 2014;37(Supplement 1):S81-90.

4. Poomalar GK. Changing trends in management of gestational diabetes mellitus. World J Diabetes. 2015;6(2):284-95. doi: https://doi.org/10.4239/wjd. v6.i2.284.

5. Vounzoulaki E, Khunti K, Abner SC, Tan BK, Davies MJ, Gillies CL. Progression to type 2 diabetes in women with a known history of gestational diabetes: systematic review and meta-analysis. BMJ. 2020;13(369): m1361. https://doi.org/10.1136/bmj. $\mathrm{m} 1361$.

6. Yuen L, Saeedi P, Riaz M, Karuranga S, Divakar H, Levitt N, Yang X, Simmons D. Projections of the prevalence of hyperglycaemia in pregnancy in 2019 and beyond: Results from the International Diabetes Federation Diabetes Atlas, 9th edition. Diabetes Res Clin Pract. 2019;157:107841.

7. Reichetzeder C, Dwi Putra SE, Li J, Hocher B. Developmental origins of disease-crisis precipitates change. Cell Physiol Biochem. 2016;39(3): 919-38. https://doi.org/10.1159/000447801.

8. Tian M, Reichetzeder C, Li J, Hocher B. Low birth weight, a risk factor for diseases in later life, is a surrogate of insulin resistance at birth. J Hypertens. 2019;37(11):2123-34. https://doi.org/10.1097/HJH. 0000000000002156.

9. Akinci B, Celtik A, Genc S, Yener S, Demir T, Secil M, Kebapcilar L, Yesil S. Evaluation of postpartum carbohydrate intolerance and cardiovascular risk factors in women with gestational diabetes. Gynecol Endocrinol. 2011;27(5):361-7. https://doi.org/ $10.3109 / 09513590.2010 .492885$.

10. Akinci B, Celtik A, Yener S, Yesil S. Prediction of developing metabolic syndrome after gestational diabetes mellitus. Fertil Steril. 2010;93(4):1248-54. https://doi.org/10.1016/j.fertnstert.2008.12.007.

11. Akinci B, Celtik A, Yuksel F, Genc S, Yener S, Secil M, Ozcan MA, Yesil S. Increased osteoprotegerin levels in women with previous gestational diabetes developing metabolic syndrome. Diabetes Res Clin
Pract. 2011;91(1):26-31. https://doi.org/10.1016/j. diabres.2010.09.028.

12. Hartling L, Dryden DM, Guthrie A, Muise M, Vandermeer B, Donovan L. Benefits and harms of treating gestational diabetes mellitus: a systematic review and meta-analysis for the U.S. Preventive Services Task Force and the National Institutes of Health Office of Medical Applications of Research. Ann Intern Med. 2013;159(2):123-9. https://doi. org/10.7326/0003-4819-159-2-201307160-00661.

13. Schäfer-Graf UM, Gembruch U, Kainer F, Groten T, Hummel S, Hösli I, Grieshop M, Kaltheuner M, Bührer C, Kautzky-Willer A, Laubner K, BancherTodesca D. Gestational diabetes mellitus (GDM)diagnosis, treatment and follow-up guideline of the DDG and DGGG (S3 Level, AWMF Registry Number 057/008, February 2018). Geburtshilfe Frauenheilkd. 2018;78(12):1219-31. https://doi.org/10. 1055/a-0659-2596.

14. Greenberg J. The relationship between maternal glycemia and perinatal outcome. Obstet Gynecol. 2011;117(5):1230. https://doi.org/10.1097/AOG. Ob013e3182176774.

15. International Diabetes Federatio. IDF GDM model of care: implementation protocol: guidelines for healthcare professionals. Available at: https://www. idf.org/e-library/guidelines/77-idf-gdm-model-ofcare-implementation-protocol-guidelines-for/ healthcareprofessionals.html

16. National Institute for Health and Care Excellence. Diabetes in pregnancy: management from preconception to the postnatal period (NICE guideline). London: NICE; 2015. https://www.nice.org.uk/ guidance/ng3

17. American Diabetes Association. 14. Management of diabetes in pregnancy: standards of medical care in diabetes-2019. Diabetes Care. 2019;42(Supplement 1):S165-72.

18. Nicholson W, Baptiste-Roberts K. Oral hypoglycaemic agents during pregnancy: the evidence for effectiveness and safety. Best Pract Res Clin Obstet Gynaecol. 2011;25(1):51-63. https://doi.org/10. 1016/j.bpobgyn.2010.10.018.

19. Conway DL, Gonzales O, Skiver D. Use of glyburide for the treatment of gestational diabetes: the San Antonio experience. J Matern Fetal Neonatal Med. 2004;15(1):51-5. https://doi.org/10.1080/ 14767050310001650725 .

20. Zeng Y, Chen Y, et al. Clinical progress of oral hypoglycemic agents in the treatment of gestational diabetes mellitus. Mater Child Health Care China. 2013;28:1206-10. 
21. Hellmuth E, Damm P, Mølsted-Pedersen L. Oral hypoglycaemic agents in 118 diabetic pregnancies. Diabet Med. 2000;17(7):507-11. https://doi.org/10. 1046/j.1464-5491.2000.00314.x.

22. Rowan JA, Hague WM, Gao W, Battin MR, Moore MP. MiG trial investigator. Metformin versus insulin for the treatment of gestational diabetes. $\mathrm{N}$ Engl J Med. 2008;358(19):2003-15. https://doi.org/10. 1056/NEJMoa0707193.

23. Zeng YC, Li MJ, Chen Y, Jiang L, Wang SM, Mo XL, $\mathrm{Li}$ BY. The use of glyburide in the management of gestational diabetes mellitus: a meta-analysis. Adv Med Sci. 2014;59(1):95-101. https://doi.org/10. 1016/j.advms.2014.03.001.

24. Kalra B, Gupta Y, Singla R, Kalra S. Use of oral antidiabetic agents in pregnancy: a pragmatic approach. N Am J Med Sci. 2015;7(1):6-12. https://doi.org/10. 4103/1947-2714.150081.

25. Ghomian N, Vahed SHM, Firouz S, Yaghoubi MA, Mohebbi M, Sahebkar A. The efficacy of metformin compared with insulin in regulating blood glucose levels during gestational diabetes mellitus: a randomized clinical trial. J Cell Physiol. 2019;234(4): 4695-701. https://doi.org/10.1002/jcp.27238.

26. Behrashi M, Samimi M, Ghasemi T, Saberi F, Atoof F. Comparison of glibenclamide and insulin on neonatal outcomes in pregnant women with gestational diabetes. Int J Prev Med. 2016;22(7):88. https://doi.org/10.4103/2008-7802.184502.

27. Mirzamoradi M, Heidar Z, Faalpoor Z, Naeiji Z, Jamali R. Comparison of glyburide and insulin in women with gestational diabetes mellitus and associated perinatal outcome: a randomized clinical trial. Acta Med Iran. 2015;53(2):97-103.

28. Ruholamin S, Eshaghian S, Allame Z. Neonatal outcomes in women with gestational diabetes mellitus treated with metformin in compare with insulin: a randomized clinical trial. J Res Med Sci. 2014;19(10):970-5.

29. Mesdaghinia E, Samimi M, Homaei Z, Saberi F, Moosavi SG, Yaribakht M. Comparison of newborn outcomes in women with gestational diabetes mellitus treated with metformin or insulin: a randomised blinded trial. Int J Prev Med. 2013;4(3): 327-33.

30. Niromanesh S, Alavi A, Sharbaf FR, Amjadi N, Moosavi S, Akbari S. Metformin compared with insulin in the management of gestational diabetes mellitus: a randomized clinical trial. Diabetes Res Clin Pract. 2012;98(3):422-9. https://doi.org/10. 1016/j.diabres.2012.09.031.
31. Sénat MV, Affres H, Letourneau A, Coustols-Valat M, Cazaubiel M, Legardeur H, Jacquier JF, Bourcigaux N, Simon E, Rod A, Héron I, Castera V, Sentilhes L, Bretelle F, Rolland C, Morin M, Deruelle P, De Carne C, Maillot F, Beucher G, Verspyck E, Desbriere R, Laboureau S, Mitanchez D, Bouyer J, Groupe de Rechercheen Obstétrique et Gynécologie (GROG). Effect of glyburide vs subcutaneous insulin on perinatal complications among women with gestational diabetes: a randomized clinical trial. JAMA. 2018;319(17):1773-80. https://doi.org/10. 1001/jama.2018.4072.

32. Eid SR, et al. Is metformin a viable alternative to insulin in the treatment of gestational diabetes mellitus (GDM)? Comparison of maternal and neonatal outcomes. Egypt Pediatric Assoc Gazette. 2018;66(1):15-21.

33. Lain KY, Garabedian MJ, Daftary A, Jeyabalan A. Neonatal adiposity following maternal treatment of gestational diabetes with glyburide compared with insulin. Am J Obstet Gynecol. 2009;200(5):501. https://doi.org/10.1016/j.ajog.2009.02.038 (e1-e6).

34. Ogunyemi D, Jesse M, Davidson M. Comparison of glyburide versus insulin in management of gestational diabetes mellitus. Endocr Pract. 2007;13(4): 427-8. https://doi.org/10.4158/EP.13.4.427.

35. Langer O, Conway DL, et al. A comparison of glyburide versus insulin in women with gestational diabetes mellitus. New Eng J Med. 2000;343(16): 1134-8.

36. Tertti K, Eskola E, Rönnemaa T, Haataja L. Neurodevelopment of two-year-old children exposed to metformin and insulin in gestational diabetes mellitus. J Dev Behav Pediatr. 2015;36(9):752-7. https://doi.org/10.1097/DBP.0000000000000230.

37. Ijäs H, Vääräsmäki M, Saarela T, Keravuo R, Raudaskoski T. A follow-up of a randomised study of metformin and insulin in gestational diabetes mellitus: growth and development of the children at the age of 18 months. BJOG. 2015;122(7):994-1000. https://doi.org/10.1111/1471-0528.12964.

38. Tertti K, Laine K, Ekblad U, Rinne V, Rönnemaa T. The degree of fetal metformin exposure does not influence fetal outcome in gestational diabetes mellitus. Acta Diabetol. 2014;51(5):731-8. https:// doi.org/10.1007/s00592-014-0570-6.

39. Tertti K, Ekblad U, Koskinen P, Vahlberg T, Rönnemaa T. Metformin vs. insulin in gestational diabetes. A randomized study characterizing metformin patients needing additional insulin. Diabetes Obes Metab. 2013;15(3):246-51. https:// doi.org/10.1111/dom.12017. 
40. Ijäs H, Vääräsmäki M, Morin-Papunen L, Keravuo R, Ebeling T, Saarela T, Raudaskoski T. Metformin should be considered in the treatment of gestational diabetes: a prospective randomised study. BJOG. 2011;118(7):880-5. https://doi.org/10.1111/ j.1471-0528.2010.02763.x.

41. Spaulonci CP, Bernardes LS, Trindade TC, Zugaib M, Francisco RP. Randomized trial of metformin vs insulin in the management of gestational diabetes. Am J Obstet Gynecol. 2013;209(1):34.e1-7. https:// doi.org/10.1016/j.ajog.2013.03.022.

42. Silva JC, Fachin DR, Coral ML, Bertini AM. Perinatal impact of the use of metformin and glyburide for the treatment of gestational diabetes mellitus. J Perinat Med. 2012;40(3):225-8. https://doi.org/10. 1515/jpm-2011-0175.

43. Silva JC, Pacheco C, Bizato J, de Souza BV, Ribeiro TE, Bertini AM. Metformin compared with glyburide for the management of gestational diabetes. Int J Gynaecol Obstet. 2010;111(1):37-40. https:// doi.org/10.1016/j.ijgo.2010.04.028.

44. Silva JC, Bertini AM, Taborda W, Becker F, Bebber FR, Aquim GM, Viesi JM. Glibenclamida no tratamento do diabete melito gestacional em estudo comparado à insulina [Glibenclamide in the treatment for gestational diabetes mellitus in a compared study to insulin]. Arq Bras Endocrinol Metabol. 2007;51(4):541-6. https://doi.org/10. 1590/s0004-27302007000400007 (Portuguese).

45. Bertini AM, Silva JC, Taborda W, Becker F, Lemos Bebber FR, Zucco Viesi JM, Aquim G, Engel RT. Perinatal outcomes and the use of oral hypoglycemic agents. J Perinat Med. 2005;33(6):519-23. https://doi.org/10.1515/JPM.2005.092.

46. Arshad R, Khanam S, Shaikh F, Karim N. Feto-maternal outcomes and glycemic control in metformin versus insulin treated gestational diabetics. Pak J Med Sci. 2017;33(5):1182-7. https://doi.org/10. 12669/pjms.335.13286.

47. Hamadani AL, Zahid S, Butt ZB. Metformin versus Insulin treatment in gestational diabetes in pregnancy and their effects on neonatal birthweight. PJMHS. 2017;11:914-6.

48. Ainuddin J, Karim N, Hasan AA, Naqvi SA. Metformin versus insulin treatment in gestational diabetes in pregnancy in a developing country: a randomized control trial. Diabetes Res Clin Pract. 2015;107(2):290-9. https://doi.org/10.1016/j. diabres.2014.10.001.

49. Hassan JA, Nasim K, Zaman S. Metformin prevents macrosomia and neonatal morbidity in gestational diabetes. Pak J Med Sci. 2012;28:384-9.
50. Subhash Somani P, et al. Treatment of gestational diabetes mellitus: insulin or metformin? J Evolut Med Dent Sci. 2016;5(63):4423-9.

51. George A, Mathews JE, Sam D, Beck M, Benjamin SJ, Abraham A, Antonisamy B, Jana AK, Thomas N. Comparison of neonatal outcomes in women with gestational diabetes with moderate hyperglycaemia on metformin or glibenclamide-a randomised controlled trial. Aust N Z J Obstet Gynaecol. 2015;55(1):47-52. https://doi.org/10.1111/ajo. 12276.

52. Tempe A, Mayanglambam RD. Glyburide as treatment option for gestational diabetes mellitus. J Obstet Gynaecol Res. 2013;39(6):1147-52. https://doi. org/10.1111/jog.12042.

53. Anjalakshi C, Balaji V, Balaji MS, Seshiah V. A prospective study comparing insulin and glibenclamide in gestational diabetes mellitus in Asian Indian women. Diabetes Res Clin Pract. 2007;76(3): 474-5. https://doi.org/10.1016/j.diabres.2006.09. 031.

54. Saleh HS, Abdelsalam WA, Mowafy HE, Abd ElHameid AA. Could metformin manage gestational diabetes mellitus instead of insulin? Int J Reprod Med. 2016;2016:3480629. https://doi.org/10.1155/ 2016/3480629.

55. Borg H, Ezat S. Metformin opposed to insulin in the management of gestational diabetes. Res Obstet Gynecol. 2016;4:17-26.

56. Ashoush S, El-Said M, Fathi H, Abdelnaby M. Identification of metformin poor responders, requiring supplemental insulin, during randomization of metformin versus insulin for the control of gestational diabetes mellitus. J Obstet Gynaecol Res. 2016;42(6):640-7. https://doi.org/10.1111/jog. 12950.

57. Moore LE, Clokey D, Rappaport VJ, Curet LB. Metformin compared with glyburide in gestational diabetes: a randomized controlled trial. Obstet Gynecol. 2010;115(1):55-9. https://doi.org/10. 1097/AOG.0b013e3181c52132.

58. Moore LE, Briery CM, Clokey D, Martin RW, Williford NJ, Bofill JA, Morrison JC. Metformin and insulin in the management of gestational diabetes mellitus: preliminary results of a comparison. J Reprod Med. 2007;52(11):1011-5.

59. Wouldes TA, Battin M, Coat S, Rush EC, Hague WM, Rowan JA. Neurodevelopmental outcome at 2 years in offspring of women randomised to metformin or insulin treatment for gestational diabetes. Arch Dis Child Fetal Neonatal Ed. 2016;101(6):F488-93. https://doi.org/10.1136/archdischild-2015-309602. 
60. Rowan JA, Hague WM, Gao W, Battin MR, Moore $\mathrm{MP}, \mathrm{MiG}$ Trial Investigators. Metformin versus insulin for the treatment of gestational diabetes. N Engl J Med. 2008;358(19):2003-15. https://doi. org/10.1056/NEJMoa0707193.

61. Marques P, Carvalho MR, Pinto L, Guerra S. Metformin safety in the management of gestational diabetes. Endocr Pract. 2014;20(10):1022-31. https://doi.org/10.4158/EP14018.OR.

62. Simeonova-Krstevska S, Bogoev M, Bogoeva K, Zisovska E, Samardziski I, Velkoska-Nakova V, Livrinova V, Todorovska I, Sima A, Blazevska-Siljanoska V. Maternal and neonatal outcomes in pregnant women with gestational diabetes mellitus treated with diet, metformin or insulin. Open Access Maced J Med Sci. 2018;6(5):803-7. https:// doi.org/10.3889/oamjms.2018.200.

63. Nachum Z, Zafran N, Salim R, Hissin N, Hasanein J, Gam Ze Letova Y, Suleiman A, Yefet E. Glyburide versus metformin and their combination for the treatment of gestational diabetes mellitus: a randomized controlled study. Diabetes Care. 2017;40(3):332-7. https://doi.org/10.2337/dc162307.

64. Rena G, Hardie DG, Ewan RP. The mechanism of action of metformin. Diabetologia. 2017;60(9): 1577-85. https://doi.org/10.1007/s00125-017-4342$\mathrm{z}$.

65. Scarpello JH, Howlett HC. Metformin therapy and clinical uses. Diab Vasc Dis Res. 2008;5(3):157-67. https://doi.org/10.3132/dvdr.2008.027.

66. Eyal S, Easterling TR, Carr D, Umans JG, Miodovnik M, Hankins GD, Clark SM, Risler L, Wang J, Kelly EJ, Shen DD, Hebert MF. Pharmacokinetics of metformin during pregnancy. Drug Metab Dispos. 2010;38(5):833-40. https://doi.org/10.1124/dmd. 109.031245 .

67. Landi SN, Radke S, Boggess K, Engel SM, Stürmer T, Howe AS, Jonsson FM. Comparative effectiveness of metformin versus insulin for gestational diabetes in New Zealand. Pharmacoepidemiol Drug Saf. 2019;28(12):1609-19. https://doi.org/10.1002/pds. 4907 .

68. Wang X, Liu W, Chen H, Chen Q. Comparison of insulin, metformin, and glyburide on perinatal complications of gestational diabetes mellitus: a systematic review and meta-analysis. Gynecol Obstet Invest. 2021;86(3):218-30. https://doi.org/ $10.1159 / 000515893$.

69. Guo L, Ma J, Tang J, Hu D, Zhang W, Zhao X. Comparative efficacy and safety of metformin, glyburide, and insulin in treating gestational diabetes mellitus: a meta-analysis. J Diabetes Res.
2019;4(2019):9804708. https://doi.org/10.1155/ $2019 / 9804708$.

70. Bao LX, Shi WT, Han YX. Metformin versus insulin for gestational diabetes: a systematic review and meta-analysis. J Matern Fetal Neonatal Med. 2021;34(16):2741-53. https://doi.org/10.1080/ 14767058.2019.1670804.

71. Li G, Zhao S, Cui S, Li L, Xu Y, Li Y. Effect comparison of metformin with insulin treatment for gestational diabetes: a meta-analysis based on RCTs. Arch Gynecol Obstet. 2015;292(1):111-20. https:// doi.org/10.1007/s00404-014-3566-0.

72. Kitwitee P, Limwattananon S, Limwattananon C, Waleekachonlert O, Ratanachotpanich T, Phimphilai M, Nguyen TV, Pongchaiyakul C. Metformin for the treatment of gestational diabetes: an updated meta-analysis. Diabetes Res Clin Pract. 2015;109(3):521-32. https://doi.org/10.1016/j. diabres.2015.05.017.

73. Desoye G, Nolan CJ. The fetal glucose steal: an underappreciated phenomenon in diabetic pregnancy. Diabetologia. 2016;59(6):1089-94. https:// doi.org/10.1007/s00125-016-3931-6.

74. Liang HL, Ma SJ, Xiao YN, Tan HZ. Comparative efficacy and safety of oral antidiabetic drugs and insulin in treating gestational diabetes mellitus: an updated PRISMA-compliant network meta-analysis. Medicine (Baltimore). 2017;96(38): e7939. https:// doi.org/10.1097/MD.0000000000007939.

75. Balani J, Hyer SL, Rodin DA, Shehata H. Pregnancy outcomes in women with gestational diabetes treated with metformin or insulin: a case-control study. Diabet Med. 2009;26(8):798-802. https://doi. org/10.1111/j.1464-5491.2009.02780.x.

76. Tertti K, Ekblad U, Vahlberg T, Rönnemaa T. Comparison of metformin and insulin in the treatment of gestational diabetes: a retrospective, case-control study. Rev Diabet Stud. 2008;5(2):95-101. https:// doi.org/10.1900/RDS.2008.5.95.

77. Farrar D, Simmonds M, Bryant M, Sheldon TA, Tuffnell D, Golder S, Lawlor DA. Treatments for gestational diabetes: a systematic review and metaanalysis. BMJ Open. 2017;7(6): e015557. https:// doi.org/10.1136/bmjopen-2016-015557.

78. Butalia S, Gutierrez L, Lodha A, Aitken E, Zakariasen A, Donovan L. Short-and long-term outcomes of metformin compared with insulin alone in pregnancy: a systematic review and meta-analysis. Diabet Med. 2017;34(1):27-36. https://doi.org/10. 1111/dme.13150.

79. Yu F, Lv L, Liang Z, Wang Y, Wen J, Lin X, Zhou Y, Mai C, Niu J. Continuous glucose monitoring 
effects on maternal glycemic control and pregnancy outcomes in patients with gestational diabetes mellitus: a prospective cohort study. J Clin Endocrinol Metab. 2014;99(12):4674-82. https://doi.org/ 10.1210/jc.2013-4332.

80. Tarry-Adkins JL, Aiken CE, Ozanne SE. Comparative impact of pharmacological treatments for gestational diabetes on neonatal anthropometry independent of maternal glycaemic control: a systematic review and meta-analysis. PLoS Med. 2020;17(5): e1003126. https://doi.org/10.1371/ journal.pmed.1003126.

81. Poolsup N, Suksomboon N, Amin M. Efficacy and safety of oral antidiabetic drugs in comparison to insulin in treating gestational diabetes mellitus: a meta-analysis. PLoS One. 2014;9(10): e109985. https://doi.org/10.1371/journal.pone.0109985.

82. Jiang YF, Chen XY, Ding T, Wang XF, Zhu ZN, Su SW. Comparative efficacy and safety of OADs in management of GDM: network meta-analysis of randomized controlled trials. J Clin Endocrinol Metab. 2015;100(5):2071-80. https://doi.org/10. 1210/jc. 2014-4403.

83. Amin M, Suksomboon N, Poolsup N, Malik O. Comparison of glyburide with metformin in treating gestational diabetes mellitus: a systematic review and meta-analysis. Clin Drug Investig. 2015;35(6):343-51. https://doi.org/10.1007/ s40261-015-0289-3.

84. Hebert MF, Ma X, Naraharisetti SB, Krudys KM, Umans JG, Hankins GD, Caritis SN, Miodovnik M, Mattison DR, Unadkat JD, Kelly EJ, Blough D, Cobelli C, Ahmed MS, Snodgrass WR, Carr DB, Easterling TR, Vicini P. Obstetric-fetal pharmacology research unit network. Are we optimizing gestational diabetes treatment with glyburide? The pharmacologic basis for better clinical practice. Clin Pharmacol Ther. 2009;85(6):607-14. https://doi. org/10.1038/clpt.2009.5.

85. Melamed N, Yogev Y. Can pregnant diabetics be treated with glyburide? Womens Health (Lond). 2009;5(6):649-58. https://doi.org/10.2217/whe.09. 55.

86. Ryu RJ, Hays KE, Hebert MF. Gestational diabetes mellitus management with oral hypoglycemic agents. Semin Perinatol. 2014;38(8):508-15. https:// doi.org/10.1053/j.semperi.2014.08.012.

87. Bishop KC, Harris BS, Boyd BK, Reiff ES, Brown L, Kuller JA. Pharmacologic treatment of diabetes in pregnancy. Obstet Gynecol Surv. 2019;74(5): $289-97$. 0000000000000671.
88. Sinai Talaulikar V, Tang T, Yasmin E. Role of metformin in women's health: review of its current place in clinical practice and emerging indications for future. Obstet Gynecol Surv. 2016;71(5):307-17. https://doi.org/10.1097/OGX.0000000000000312.

89. Kremer CJ, Duff P. Glyburide for the treatment of gestational diabetes. Am J Obstet Gynecol. 2004;190(5):1438-9. https://doi.org/10.1016/j.ajog. 2004.02.032.

90. Gandhi P, Bustani R, Madhuvrata P, Farrell T. Introduction of metformin for gestational diabetes mellitus in clinical practice: has it had an impact? Eur J Obstet Gynecol Reprod Biol. 2012;160(2): 147-50. https://doi.org/10.1016/j.ejogrb.2011.11. 018.

91. Goh JE, Sadler L, Rowan J. Metformin for gestational diabetes in routine clinical practice. Diabet Med. 2011;28(9):1082-7. https://doi.org/10.1111/j. 1464-5491.2011.03361.x.

92. Abernethy PJ, Thayer R, Taylor AW. Acute and chronic responses of skeletal muscle to endurance and sprint exercise. A review. Sports Med. 1990;10(6):365-89. https://doi.org/10.2165/ 00007256-199010060-00004.

93. Jensen TE, Richter EA. Regulation of glucose and glycogen metabolism during and after exercise. J Physiol. 2012;590(5):1069-76. https://doi.org/10. 1113/jphysiol.2011.224972.

94. Sathyapalan T, Mellor D, Atkin SL. Obesity and gestational diabetes. Semin Fetal Neonatal Med. 2010;15(2):89-93. https://doi.org/10.1016/j.siny. 2009.09.002.

95. Kershaw EE, Flier JS. Adipose tissue as an endocrine organ. J Clin Endocrinol Metab. 2004;89(6): 2548-56. https://doi.org/10.1210/jc.2004-0395.

96. Ye J. Mechanisms of insulin resistance in obesity. Front Med. 2013;7(1):14-24. https://doi.org/10. 1007/s11684-013-0262-6.

97. Barbour LA, McCurdy CE, Hernandez TL, Kirwan JP, Catalano PM, Friedman JE. Cellular mechanisms for insulin resistance in normal pregnancy and gestational diabetes. Diabetes Care. 2007;30(Suppl 2): S112-9. https://doi.org/10.2337/dc07-s202.

98. von Websky K, Hasan AA, Reichetzeder C, Tsuprykov $\mathrm{O}$, Hocher $\mathrm{B}$. Impact of vitamin $\mathrm{D}$ on pregnancy-related disorders and on offspring outcome. J Steroid Biochem Mol Biol. 2018;180:51-64. https://doi.org/10.1016/j.jsbmb.2017.11.008.

99. Wang L, Zhang C, Song Y, Zhang Z. Serum vitamin $\mathrm{D}$ deficiency and risk of gestational diabetes 
mellitus: a meta-analysis. Arch Med Sci. 2020;16(4): 742-51. https://doi.org/10.5114/aoms.2020.94433.

100. Rajput R, Vohra S, Nanda S, Rajput M. Severe 25(OH)vitamin-D deficiency: a risk factor for development of gestational diabetes mellitus. Diabetes Metab Syndr. 2019;13(2):985-7. https://doi. org/10.1016/j.dsx.2019.01.004.

101. Xia J, Song Y, Rawal S, Wu J, Hinkle SN, Tsai MY, Zhang C. Vitamin D status during pregnancy and the risk of gestational diabetes mellitus: a longitudinal study in a multiracial cohort. Diabetes Obes Metab. 2019;21(8):1895-905. https://doi.org/10. 1111/dom.13748.

102. Zhang Y, Gong Y, Xue H, Xiong J, Cheng G. Vitamin $\mathrm{D}$ and gestational diabetes mellitus: a systematic review based on data free of Hawthorne effect. BJOG. 2018;125(7):784-93. https://doi.org/10. 1111/1471-0528.15060.

103. Wang M, Chen Z, Hu Y, Wang Y, Wu Y, Lian F, Li H, Yang J, Xu X. The effects of vitamin D supplementation on glycemic control and maternal-neonatal outcomes in women with established gestational diabetes mellitus: a systematic review and metaanalysis. Clin Nutr. 2021;40(5):3148-57. https:// doi.org/10.1016/j.clnu.2020.12.016.

104. Chen X, Chu C, Doebis C, von Baehr V, Hocher B. Sex dependent association of vitamin $\mathrm{D}$ with insulin resistance. J Clin Endocrinol Metab. 2021. https://doi.org/10.1210/clinem/dgab213.

105. Vivanti AJ, Monier I, Salakos E, Elie C, Tsatsaris V, Senat MV, Jani J, Jouannic JM, Winer N, Zeitlin J, Mougneaud C, Souberbielle JC, Courbebaisse M, Benachi A. Vitamin D and pregnancy outcomes: overall results of the FEPED study. J Gynecol Obstet Hum Reprod. 2020;49(8):101883. https://doi.org/ 10.1016/j.jogoh.2020.101883.

106. Tehrani HG, Mostajeran F, Banihashemi B. Effect of vitamin $D$ supplementation on the incidence of gestational diabetes. Adv Biomed Res. 2017;14(6): 79. https://doi.org/10.4103/2277-9175.210658.

107. Rodrigues MRK, Lima SAM, Mazeto GMFDS, Calderon IMP, Magalhães CG, Ferraz GAR, Molina AC, Costa RAA, Nogueira VDSN, Rudge MVC. Efficacy of vitamin $\mathrm{D}$ supplementation in gestational diabetes mellitus: systematic review and meta-analysis of randomized trials. PLoS One. 2019;143: e0213006. https://doi.org/10.1371/journal.pone.0213006.

108. Al-Ajlan A, Al-Musharaf S, Fouda MA, Krishnaswamy S, Wani K, Aljohani NJ, Al-Serehi A, Sheshah E, Alshingetti NM, Turkistani IZ, Afrah Alharbi A, Alraqebah BA, Ali AM, Al-Saeed G, Al-Daghri NM. Lower vitamin D levels in Saudi pregnant women are associated with higher risk of developing GDM. BMC Pregnancy Childbirth. 2018;18(1):86. https:// doi.org/10.1186/s12884-018-1723-3.

109. Ashrafi M, Gosili R, Hosseini R, Arabipoor A, Ahmadi J, Chehrazi M. Risk of gestational diabetes mellitus in patients undergoing assisted reproductive techniques. Eur J Obstet Gynecol Reprod Biol. 2014;176:149-52. https://doi.org/10.1016/j.ejogrb. 2014.02.009.

110. Bosdou JK, Anagnostis P, Goulis DG, Lainas GT, Tarlatzis BC, Grimbizis GF, Kolibianakis EM. Risk of gestational diabetes mellitus in women achieving singleton pregnancy spontaneously or after ART: a systematic review and meta-analysis. Hum Reprod Update. 2020;26(4):514-44. https://doi.org/10. 1093/humupd/dmaa011.

111. Lei LL, Lan YL, Wang SY, Feng W, Zhai ZJ. Perinatal complications and live-birth outcomes following assisted reproductive technology: a retrospective cohort study. Chin Med J (Engl). 2019;132(20): 2408-16. 0000000000000484 .

112. Márton V, Zádori J, Keresztúri A, Kozinszky Z. Associated perinatal determinants of vanishing twin pregnancies achieved by in vitro fertilization vs. spontaneous conception. Arch Gynecol Obstet. 2020;301(2):491-8. https://doi.org/10.1007/ s00404-020-05448-y.

113. Thomakos $\mathrm{P}$, Kepaptsoglou O, Korantzis A, Trouva A, Sklavounos I, Trouvas D, Taraoune N, Barreto C, Zoupas CS. The diagnosis of gestational diabetes mellitus and its impact on in vitro fertilization pregnancies. A pilot study. J Diabetes Complications. 2021;35(6):107914. https://doi.org/10.1016/j. jdiacomp.2021.107914.

114. Hague WM, Davoren PM, Oliver J, Rowan J. Contraindications to use of metformin. Metformin may be useful in gestational diabetes. BMJ. 2003;326(7392):762. 